\title{
The Human Resource Management and the Profitability, in Turkish Banking Sector: Evidence Within the "Leap Period"
}

\author{
İhsan Oğuz BAKKALBAŞI \\ Faculty of Political Science, Marmara University, 34820, Beykoz, Istanbul, Turkey
}

\begin{abstract}
Since the concurrence reached its highest level at the last decades of the 20th century, the firms are in the search of gaining the competitive advantage. After have seen the impact of the strategic resources, scholar have focused to find the new ones. Human resource management had a considerable potential to contribute to the firm performance. In spite of evidence the relationship between the HRM and the firm performance, there are still some uncertainties: First, is it really acceptable to trust the perceptions of the respondents, particularly since they evaluate both HRM and the performance. And secondly, is it really certain that HRM ensures the profitability (but not the profitability ensures the HRM). In order to answer these questions, the annual activity reports (between 2010-2019) of the commercial banks in Turkey are analyzed. The data gathered from the HRM sections and the financial sheets are compared. Based on the intensity of new HRM practices starting and their impact on ROA, it is argued that HRM is one the factors that ensure the profitability, when it is driven in a leap period.

Keywords: Strategic human resource management, human resource management, firm performance, ROA, leap period

DOI: $10.7176 / \mathrm{EJBM} / 13-8-08$
\end{abstract}

Publication date: April $30^{\text {th }} 2021$

\section{Introduction}

It has been reported several times that the human resource managements (HRM) have positive impact on the firm performance (Huselid 1995; Kim et.al., 2018; Huselid \& Becker, 1997; Ichniowski, Shaw \& Prennushi, 1997) and on the related organizational (strategic) outcomes (Sun, Aryee \& Law, 2007; Kılıçarslan \& Marşap, 2018). The individual practices influence the firm performance (Delaney \& Huselid, 1996; Harel \& Tzafrir, 1999) and the bundles that contain a group of HRM practices have bigger impact on the firm performance (Delaney \& Huselid, 1996; Barrette \& Carrière, 2003; Carrière \& Barette, 2005).

The impact of the HRM's has been investigated not only in private companies of western industrialized countries, but also in non-profit organizations (Balk, Schinnenburg \& Handy, 2013; Delaney \& Huselid, 1996), in different geographies and cultures with different industrialization levels all around the world (Bae \& Lawler, 2000; Rose \& Kumar, 2006; Liang, Marler \& Cui, 2012: 59-60; Chow, Huang, Liu, 2008). The HRM practices are obviously strategic for the companies since their positive impact on the performance within the different conditions (Gollan, Kalfa \& Xu, 2015: 158).

However, further studies are still needed in order to dissipate the doubts. First, HR practices should be actualized. HRM practices that have the potential to contribute the firm performance were used until recently. They are called as the "HPWP/HPWS (High Performant Work Practices or Systems)", "Innovative HRM practices" or "Commitment-oriented HRM practices". Although these practices as well as the papers based on them, were persuasive for the positive impact between HRM and firm performance as well as retention, loyalty or job satisfaction of employees (Ichniowski, Shaw \& Prennushi, 1997); today, it is impossible to be sure that these practices still have potential to ensure those outcomes. Beside obsoleteness*, they were extensively driven, probably they cannot give the competitiveness anymore. Thus, (if) they lost their potential to be competitive, newer terms should be described and put in the practice in order to evaluate of effectiveness of HRM.

Secondly, most of the papers trusts merely on the perceptions of the respondents. But worse; generally, the respondents, evaluate both two different variables; "HRM" and "the organizational performance" (Huselid, 1995: 640; Becker \& Gerhart, 1996; Truss 2001:1121). There are two important "disputable" points here: unique respondent answers the questions about both dependent and independent variables and further, all evaluations are based on the perceptions. Hence, it could be better to draw the "evidence" from the perceptions' influence.

In addition, boundaries of the scope (cultural and industrialization i.e.) should be enlarged (Kramar \& Parry, 2014 Festing, 2012: 38). Although there are several papers argue the HRM-performance relation in different contexts, different ones can and should be added, with the differences of the culture, the geography, and the time, in order to generalization.

Lastly, the causality between HRM and performance is not still certainly found (Huselid, 1995: 640; Guest, Michie, Conway \& Sheehan, 2003; Becker \& Huselid, 2006: 899; Gerhart, 2005: 177; Liang, Marler \& Cui, 2012:

\footnotetext{
* HPWP, for example, are published by US Department of Labor in 1993, but a more detailed study would help to see that they are originally based on "In Search of Excellence" of Peters and Waterman (Delaney \& Huselid, 1996: 949)
} 
65). It is clear that the high performant firms drive high performant work practices, yet it is not clear whether the high performant work practices absolutely drive to high performant firm.

\section{Conceptual Underpinnings}

Since 80's, human resource (HR) is so important that never has been shown before (Truss \& Gratton, 1994; Schuler \& Jackson, 2005). Because the "hard competition age" has begun and industries should be adapted themselves. The companies have understood that they should use all of their resources to gain the competitive advantage (Huselid, Schuler \& Jackson, 1997). And HR had a potential to contribute to competitive force of the firm as a strategic resource "VRIO" (Becker \& Gerhart, 1996: 779; Barney \& Wright, 1998; Matei, 2013: 190; Çetintürk, 2017) in accordance with Barney's argue (Barney, 1991) or with Hamel and Prahalad's (Hamel and Prahalad, 1990) argue (Kamoche, 1996: 219, 227).

This potential makes the HRM be strategic but in meantime it triggers to new thinking; how can we manage the HR in accordance with the strategic expectations? How can we bring out the HR's strategic potential (Becker \& Gerhart, 1996: 780)?

It is revealed that the HRM is strategic as it contributes to competitive force of the firm (Bratton \& Gold 2007: 7). But what is the way to transform the strategic potential of the HR to the competitive advantage in action? If the SHRM is defined as "... the pattern of planned human resource deployments and activities intended to enable an organization to achieve its goals", the conformity with the organizational strategy and the coherence among the HR activities are clearly understood (McMahan \& Wright, 1992: 298).

But today it is clear that the strategic human resource management has a much more complex structure that based on four different fundamentals (Schuler \& Jackson, 2005):

"Vertical integration - understanding the organization and its context Horizontal integration - creating coherent HRM systems

Demonstrating effectiveness - showing how HRM systems affect organizational performance

Partnership - HR professionals working cooperatively with line managers as well as with non-management employees"

At the beginning, there were less doubts. There should be a hierarchy between the strategic plan and HRM, so, the SHRM was meaning the fitting to the strategic plan of the firm (Devanna, Fombrun \& Tichy, 1981; Miller, 1988). The Porter's theory that concerns the generic strategies was the anchor of the day (Dess \& Davis, 1984; Nayyar, 1993; Hoskisson, Hitt, Pan \& Yu, 1999: 425-426), and the HRM was charged to drive the HR practices according to the firm strategy (Schuler \& Jackson, 1987; Arthur, 1992; Youndt, et.al, 1996).

Along 15 years (approx. between 1980-1995) the papers concentrated to unfold the fitting details about the SHRM (Fox \& McLeay, 1992; Snell \& Dean 1992; Arthur, 1992; Dyer \& Reeves, 1995). The theoretical underpinning was the Porter's model. And the scholars struggled to argue that the low road strategies entail the control-oriented HRM practices while the high road strategies entail commitment-oriented HRM practices (Arthur, 1994; Youndt, et.al, 1996) in order to improve the performance. But it was not like expected (Becker \& Huselid, 2006: 901).

Concerning the fitting, there were two different axes; one was related to vertical fitting (contingency) and the second was related to the vertical+horizontal fitting (configuration) (Delery, 1998; Way \& Johnson, 2005; Rose \& Kumar, 2006). While the vertical fitting or strategic fit means the fitting between the firm strategy (Boon, Boselie, Paauwe \& Den Hartog, 2007); configurational fitting contains more factors to adapt such the organizational culture, structure, technology as the examples of the external context of the HRM of a firm (Golden \& Ramanujam, 1985; Panayotopoulou, Bourantas \& Papalexandris, 2003; Webel \& DeMarie, 2005).

Horizontal fitting consists of the internal coherence among the HRM practices. Hence either they target to control-orientation or commitment-orientation (Arthur, 1992), HRM practices should have a common direction according to the horizontal fitting (Boon, Boselie, Paauwe \& Den Hartog, 2007). The positive effect of the horizontal fitting is argued several times (Barrette \& Carrière, 2003; Carrière \& Barette, 2005).

The empirical researches could not confirm the positive effect of vertical fitting as much as we expect (Düzgün \& Çetin, 2017; Bae \& Lawler, 2000; Huselid, 1995; Chan, Shaffer \& Snape, 2004)•. However, the researchers don't erase completely the vertical effect, in their mind (Becker \& Huselid, 2006: 901). Because trusting the HRM practices on the firm performance without considering any impact of the external factors for HRM, such the firm strategy, organizational culture or leadership style, etc... seems like illogical (Gerhart, 2005: 177).

Although they don't reject the positive effect of vertical fitting, scholars in the field, gave up to analyze the vertical fitting dimension of the SHRM (contingency impact i.e.); instead, they went on to the studies that aim to

\footnotetext{
- In fact, there are still some papers aim to test or find the contingency impact on the firm performance (after 1995). But the results are complicated. The ones argue the universality and contingency in mean time (Youndt, Lepak \& Snell, 1996; Delery \& Doty, 1996); another one who argues "partially" the contingency (Chan, Shaffer \& Snape 2004) and another one who argues the contingency by using the human resources policies instead of the commitment/control-oriented HRM practices (Takeuchi, 2009).
} 
look to the relationship between commitment-oriented HRM practices on the firm performance (Ichniowski, Shaw \& Prennushi, 1997; Guest, Michie, Conway \& Sheehan, 2003).

Based on these results, the researchers shifted to the analyze the commitment-oriented HRM system and its effect on the performance, independently from the context. Yes, commitment-oriented HRM practices might positively influence the firm performance (Huselid, 1995; Delaney \& Huselid, 1996; Kim et.al., 2018; Huselid \& Becker, 1997; Chow, Huang, Liu, 2008: 701-702). Then, the papers have gone on this way until today.

Since it is revealed that the commitment-oriented HRM practices had almost always positive impact on the firm performance; the scholars and the practitioners consider this list as the universal best formula of the HRM. It means, this formula ensures the performance in any case and condition. Therefore, the HRM practices that constitute this formula, become isomorphic for all firms that aim to have the competitive advantage (Festing, 2012: 39). And if we check the papers that aim to unfold the relation between commitment-oriented HR and/or HPWP/HPWS and the firm performance, we can see that there are many firms who do it.

But in meantime, "another isomorphism" approach prevail in the management. for the firms who applicate these practices. While SHRM literature sees the commitment-oriented HRM and/or the HPWP/HPWS as the way of the HRM's contribution to the firm performance, (new) institutionalization literature claims that the isomorphism concerning the HRM practices (DiMaggio \& Powell, 1983) is due to the (new) institutionalization (Meyer \& Rowan, 1977) and not to rational decisions regarding the performance and strategic goals (McMahan \& Wright, 1992: 314). In this view, the firms, especially the ones who constitute a "population" (Hannan \& Freeman, 1977), are the subjects of the common external factors and that's why it is normal to see the common managerial reactions for the common external environment such the government decisions, similar academic back-grounds etc.... Hence, we should expect an "isomorphism" based on the (new institutionalization) between the firms that constitute a population.

That causes a discussion in the management, the isomorphism is evident among the managerial activities as well as the HRM practices, while its reasons are uncertain. What is the reason of the isomorphism: performance expectation or (new) institutional press.

This complicated structure's all dimensions are still needed to be enlighten. But me, I start with the easiest one: Does the HRM really improve the firm performance?

In order to answer to this question, we should see the positive relation between HRM practices and the firm performance but at the same time the causality relation between these two constructs. To show the relationship between HRM and the firm performance, ROA will be considered as the dependent variable and the newer HRM practices will be considered as the independent variable. With the aim of seeing the real impact of a new HRM practice, it is supposed that the sequel of a new HRM practice should be analyze.

This supposition is based on this expectation: If the HRM practices have a positive impact on the performance, there should be a changing, concerning the organizational outcomes, correspondingly the HRM (changing). The annuals offer an opportunity for unfolding both changings, because they mention the starting of all (newer) managerial activities such HRM practices. Taking this opportunity, it seems like being possible and logic to find the starting of new HRM practices and their impact on firm performance at the sequel period (year or years).

Therefore:

H1: There is a positive relation between newer HRM practices'starting and ROA.

On the other hand, to unfold the causality riddle it will be questioned whether the banks turn to HRM practices after their unprofitable year or not. If the banks consider the HRM practices as a good reaction against a profitability problem (ROA for example), it should be that they revitalize their HRM practices with the newer ones. Then:

P1: When a bank faces with the ROA problem, it increases its HRM practices with newer ones.

\section{Research:}

The newer HRM practices information was gathered from annual activity reports of commercial banks in Turkey. For testing the hypothesis as well as the proposition, the relation between the starting of newer HRM practices and the ROA were analyzed. The research was concerning the starting time and it was an opportunity for observing its impact on the performance; because they can be seen in the annuals.

On the other hand, a unique industry is chosen for the study, with the aim of the reduce the potential control variables. The factors based on the industrial differences might influence the profitability differences. Those risks are eliminated by taking a unique industry. And the unique industry is good for a research that aims to see the HRM mechanism (Becker \& Gerhart, 1996: 792).

The unique sector chosen for the research is the banking sector. The banks provide detailed and rigidly controlled annual activity reports. In fact, not only the banks but all listed companies provide such reports but the banks' reports are much more detailed and standardized. It is not first time that such reports are used for a research (Huselid, 1995: 644), but it is not widespread, either. However, since the annual activity reports contain tangible data concerning the financial sheets as well as the managerial activities including the HRM practices (Delery \& 
Doty, 1996: 814) it would be an accurate way to evaluate them for understanding the HRM practices. In addition, the HRM activities are written in a specific section with the "Human Resources Management Practices" title; it means that the HRM practices are officially mentioned in those reports.

Secondly, a bank's competitive advantage is mostly based on its HR. Because the "product (money i.e.)" is obviously standard, hence the services and the innovations, that depend mainly on the HR's performance, are the basic factors for achieving the competitive advantage (Barrette \& Carrière, 2003) and the service sector was not analyzed as much as manufacturing sector (Sun, Aryee \& Law, 2007: 558;).

And finally, in his paper Huselid, he excluded the banks because they are subject to governmental regulations (Huselid, 1995: 652). Huselid's paper (1995) is one of the most important papers in the field; because it almost completely confirmed that the relation between HRM and the firm performance. Then, it became a "breaking point" for the literature, since the papers generally focused generally to confirm the HPWS-performance relation. However, the absence of banking sector seems like missing part of the picture and me, I've tried to cover this lack, within the limits of my own capacity.

Since the all questions appear around the HRM and the performance, they should be the constructs for analyzing. Hence it might be better to see the details about the performance and the HRM, as the constructs of the study.

\subsection{Firm Performance}

Firm performance is the base of the dependent variable. Many types of performance criteria exist, but the financial ones are still more important in the eyes of the managers (Widener, 2006: 434). A superficial looking to the performance criteria shows that the operational ones are likely the best ones to reflect the managerial impact on performance (Arthur, 1994; Icniowski, Shaw \& Prennushi, 1997). Because they measure accurately the HR's contribution. However, they are not very familiar with the banking sector since there is not any clear indicator that reflects the operational performance to us. Secondly, it is not certain whether the operational criteria may be the critical indicators for the firm's performance in banking sector. And thirdly, there is not any standard data concerning the operational performance in the annual activity reports to compare the performance of banks.

On the other hand, turn-over and productivity (of HR) are the best ones to show the impact of HRM. But unfortunately, they have also the obstacles to be the dependent variable for this paper. The data regarding the turnover is not standardly announced each year; there are some lacks. Additionally, it is not certain whether the turnover number contains the non-voluntary severance like retiring or not. And lastly, it is impossible to use the data such "total credits/staff quantity" to find the employee productivity for example since the "internet banking", "call centers" or "mobile branches" have the serious parts of the ways to clients, often without employee contribution.

Therefore, the financial criteria seem like the best for evaluating the performance of banks. Although the financial criteria have a large range, the ones that are based on the (stock) market value and the profits are more important (Becker \& Gerhart, 1996). Since the Turkish stock exchange market is not as established as the occidental developed countries, I preferred to take merely one concerning the profit.

Profit is a trustworthy criterion (Fox and McLeay; 1992; Becker \& Gerhart, 1996; Widener 2006). The (private) firms are founded for the profit. Grooving, market share, quality, employee satisfaction, client satisfaction etc. all of them is important as they contribute the profit. So, the profit and the other criteria based on the profit are the trustworthy criteria to show the corporation performance. Particularly in the service industries where the performance is influenced by the HR endeavors, like banking industry, the profit is good indicator.

However, taking directly the "net margin" or "profit" would be vain because it was impossible to compare the banks, based on those criteria; since the sizes of the banks are different and the absolute values would misdirect the results. Instead; relative profitability would reflect the HRM, as well as the competitivity of banks, accurately (Fox and McLeay; 1992: 526-528).

In this "formula" I have checked the ROA, since it is a popular criterion on the eyes of the scholars as well as the managers (Dess \& Davis, 1984: 484; Delery \& Doty, 1996; Lee \& Miller, 1999; Truss, 2001; Takeuchi, 2009; Wu \& Salomon, 2016). But moreover, the banks are the firms of the financial industry, they aim to find the best way to measure their assets. Naturally all firms aim to evaluate their assets as much as they maximize their profits but it's obviously more important in the banking sector. Moreover, and more important, I have seen that the banks use the ROA for evaluate themselves.

On the other hand, it was not sufficient to see simply the profitability to analyze the HR's contribution into the concurrence capacity of the banks, since the main aim is to unfold the strategic impact of the HR. Then, I aimed to find the competitive difference of the banks. For finding that capacity, first the banks' ROAs are computed, second the industrial average is computed (by simple arithmetic average of the banks which are taken in the research) and lastly each bank's ROA is compared with the industrial average year by year. And the changings of the compared ROAs are accepted as the dependent variable of the paper. 


\subsection{Human Resources Management Practices}

What is the way to measure the HRM? It is impossible to reach any result by questioning whether the HRM functions exist or not, because yes, they are extensively exists. There is no any bank who does not applicate the classical HRM practices. It is also impossible to reach any result by questioning whether the commitment-oriented HRM practices are in action or not, because yes, they are almost commonly in action. Either they are called as the commitment-oriented HR practices or as the HPWP/HPWS; they are extensively imitated and in action: It is not logical to expect the strategic contribution from these practices (Barney, 1991; Becker \& Gerhart, 1996; Oliver, 1997: 703; Wu \& Salomon, 2016).

But, the impact of the HRM practice(s) on the firm performance, should be lightened in order to show the relationship between HRM and the performances. Therefore, the starting of the (new) practices and their impact on the performance would be the bests to look to understand the relation between the HRM and the firm performance in spite of testing the "classical HPWP/HPWS (or commitment-oriented HR practices).

On the other hand, there is a great opportunity. While they don't ordinarily mention their classic and routine HRM practices, the banks never miss to show the starting of their new HRM practices, clearly in the annuals with the aim of showing their (new) activities along the year.

In short, I have witnessed that some newer HRM practices (see below) have started during the last decade (generally) in banking industry. And I measure HRM by analyzing these newer practices. Finally, I tried to unfold the strategic impact of the HRM on the firm performance, via analyzing the impact of the newer HRM practices on the compared ROA in the banking sector. Since it is possible to see the starting of these newer practices, their strategic contribution on the performance would be measured.

Before the end of the section, a detail should be added here: most of those newer HRM practices are the components of the "talent management" that is one of the recent HRM systems. However, the relation between talent management and the performance is not analyzed, because those practices, were not simultaneously started, "in one go", either within a wide-range management technique (like talent management), but they started in different years. Sometimes one, sometimes two, sometimes more of them started in a year, but sometimes not.

However, I have also witnessed that the starting of these newer practices generally aggregates in two or three years that I called them as the "leap period". And I actually wanted to measure the impact of these leap periods on the firm performance.

What are the newer HRM practices?

- Customer oriented changing (COC) program for the HR (for the HR because all banks have or had triggered COC program but I checked whether a "sub-program" for HR exist or not)

- Centralization program for operational activities with aim to transfer personnel to the sales unit

- Talent management (I've checked whether the talent management is announced independently from its component practices or not)

- Carrier maps

- Coaching

- (Internal) mentoring

- Several assistance services for employees (for their healthy, for psychologic counselling etc..)

- Personal professional formation catalogues (in order to let the employees, choose the subjects of formation).

- Brand management

- Work-life balance projects

- Back-up plans

- Data mining programs (for HR)

- Appointments aimed to motivation (vertical or horizontal)

- Work engagement surveys, internal customer surveys, commitment surveys

- Social and cultural events

- Leadership programs for managers (any level) and even manager nominees

- Corporate culture projects

- Employee suggestions programs

- Projects of candidates from employees for hiring

- Balanced score card (if the HR department applicate any BSC program for HR)

- Six Sigma (if the HR department applicate any BSC program for HR)

- Formation as games for the new generations

- Norm staff program 


\subsection{Scope}

This study is carried out in scope of the banking sector in Turkey between 2008-2019. As I stated above, the banking sector has many advantages to be the subject of the analysis (Deephouse, 1996; Delery \& Doty, 1996). Here the reasons of the periods, with its beginning and the end:

The latest annual activity reports belong to 2019. The announcement of the 2020 annual reports will take place at the end of the April 2021; it would be late. But more important the pandemic may deviate the results. On the other hand, quarterly reports don't contain detailed and standard information and they are not rigidly surveyed either. Therefore, the best is to cut the research period in 2019.

And what about the beginning of the period; I would like to express that I actually begun the study from 2000. However, before 2008, I saw that the information provided in the annuals were not sufficiently standard for all banks. And I was not able to make a standard analysis based on this. In addition, some banks were not open before the 2008 and some of them, who were open before 2008 are not active anymore.

Although the years 2008-2019 were examined within the scope of the study, I just disclose the results between 2010-2019 by pooling them into two different groups as period 1 (2010-2014) and period 2 (2015-2019); since I obtained the most evident results by comparing these two periods.

The country choice may be another contribution to the literature; because most of the papers' scope was the western countries and enterprises, until today. It is impossible to say that there was not any study that are carried out in eastern countries in this domain, however, the quantity of such researches was limited and the eastern countries are less homogenies then the western countries, either with their cultural dimension, or with their industrialization level and style. So, it is impossible to say that the researches in a couple of eastern countries can present all eastern examples.

And the banks; the banks are the commercial banks that works in Turkey. They are not only private banks, we have publics banks also. After I have checked the reports I've decided to include the public ones; because the HR activities, with their targets, were similar, and the financial results as well. And I can say that the adding the public banks into the group doesn't change the results, but just its extent.

However, the other financial institutions such financial intermediaries, investment banks, development banks, leasing companies or financial institutions like insurance companies, are not added in the paper, with the aim to specify the group and to avoid to sectoral differences.

Furthermore, the commercial banks that have less than 10 branches, are also eliminated, since they were not nationwide organized banks. In fact, most of them were the unique agencies of the biggest global banks that don't work in Turkey.

At the end, after clarify the boundaries I have reached 20 commercial banks but one of them was founded in 2012 and I have taken it out. So, I analyzed 19 commercial banks who work in Turkey, national or international originated and public or private held.

\subsection{Works}

First, I have summarized the HRM sections of the banks' annuals (exist in the appendix). The brief data of these sections will serve to see the new HRM practices with their starting years and it would be possible to question whether the new HRM practices swarm in one or couple of years or not. Moreover, it would be possible to see the HRM intensive year or years. And it would be possible to compare these data with the ROA and ROA changing year by year.

If the quantitatively intensive newer HRM practices and the compared ROA average of the bank are in the same period (as a year, as a couple of years or more); it means that the bank's compared ROA is higher when the newer HRM practices are quantitatively more intensive (than the other period). It means that there is a positive relation between compared ROA and the HRM. That's what for the hypothesis testing.

On the other hand, if the quantity of the periods, when the bank turns towards to the HRM as a reaction against ROA problem, is higher than the other years; it means that the bank said supports the proposition. It means that the bank said consider the HRM as a weapon against the ROA problem. It means that the bank said expects that the HRM may re-improve the profitability. That's what for the proposition testing.

Either the hypothesis or the proposition, would be considered as "accepted" if the most of the banks support it. Let's look the banks and their new HRM practices with the starting years:

\section{Results:}

4.1 Positive relation between HRM and the firm performance

In table 1, the ROA values (based on the years), ROA averages (based on the five years periods), ROA averages' differences and changings (based on the five years) and the leap periods (when the starting intensity of the new HRM practices are increased) are seen. In fact, the three columns at the left are enough for seeing the relations. Does the performance of the bank improve during the leap period (when the starting intensity of the new HRM practices are increased) or not; that was the question. 


\begin{tabular}{|c|c|c|c|c|c|c|c|c|c|c|c|c|c|c|c|}
\hline BANKS & $\begin{array}{l}\text { LEAP } \\
\text { PERIOD }\end{array}$ & $\begin{array}{l}\text { ROA } \\
\text { CHANGING }\end{array}$ & DIFFERENCE & $\begin{array}{l}\text { AVERAG E } \\
2010 \cdot 2014\end{array}$ & $\begin{array}{l}\text { AVERAGE } \\
\text { 2015-2019 }\end{array}$ & 2010 & 2011 & 2012 & 2013 & 2014 & 2015 & 2016 & 2017 & 2018 & 2019 \\
\hline A & 1 & $-0,3824$ & $.0,0032$ & $\quad 0,0051$ & 0,0083 & 0,0070 & 0,0053 & 0,0098 & 0,0075 & 0,0120 & 0,0050 & 0,0006 & 0,0047 & 0,0089 & 0,0065 \\
\hline B & 2 & $-0,1514$ & $-0,0031$ & 0,0171 & 0,0202 & 0,0274 & 0,0194 & 0,0204 & 0,0173 & 0,0162 & 0,0136 & 0,0179 & 0,0206 & 0,0177 & 0,0157 \\
\hline c & 2 & $-0,1582$ & $-0,0033$ & 0,0175 & 0,0207 & 0,0295 & 0,0166 & 0,0275 & 0,0134 & 0,0168 & 0,0141 & 0,0150 & 0,0113 & 0,0210 & 0,0259 \\
\hline D & 2 & 28,8500 & 0,0070 & 0,0068 & $-0,0002$ & 0,0073 & 0,0053 & $-0,0069$ & $-0,0090$ & 0,0021 & 0,0050 & 0,0057 & 0,0072 & 0,0089 & 0,0072 \\
\hline E & 1 & $-0,1943$ & $.0,0033$ & 0,0135 & 0,0168 & 0,0187 & 0,0275 & 0,0203 & 0,0088 & 0,0088 & 0,0099 & 0,0150 & 0,0168 & 0,0169 & 0,0091 \\
\hline$F$ & 2 & 1,2067 & 0,0050 & 0,0092 & 0,0042 & $-0,0148$ & 0,0031 & 0,0143 & 0,0083 & 0,0101 & 0,0085 & 0,0086 & 0,0094 & 0,0097 & 0,0100 \\
\hline G & 1 & $-0,2409$ & $-0,0043$ & 0,0136 & 0,0180 & 0,0271 & 0,0201 & 0,0180 & 0,0122 & 0,0124 & 0,0088 & 0,0129 & 0,0141 & 0,0170 & 0,0155 \\
\hline $\mathrm{H}$ & 2 & $.0,1403$ & $.0,0020$ & 0,0180 & 0,0209 & 0,0273 & 0,0227 & 0,0201 & 0,0168 & 0,0176 & 0,0144 & 0,0188 & 0,0208 & 0,0194 & 0,0164 \\
\hline I & 1 & $-0,5677$ & $-0,0134$ & 0,0102 & 0,0236 & 0,0301 & 0,0249 & 0,0260 & 0,0222 & 0,0149 & 0,0135 & 0,0122 & 0,0139 & 0,0074 & 0,0041 \\
\hline J & 2 & $-0,5441$ & $-0,0037$ & 0,0031 & 0,0067 & 0,0154 & 0,0115 & 0,0073 & 0,0010 & $-0,0016$ & $-0,0101$ & $-0,0127$ & 0,0126 & 0,0117 & 0,0139 \\
\hline K & 1 & $-0,7384$ & $-0,0053$ & 0,0019 & 0,0072 & 0,0060 & 0,0073 & 0,0075 & 0,0116 & 0,0033 & $-0,0033$ & 0,0018 & 0,0040 & 0,0044 & 0,0024 \\
\hline L & 2 & 1,2931 & 0,0085 & 0,0150 & 0,0066 & 0,0069 & 0,0041 & 0,0109 & 0,0060 & 0,0049 & 0,0026 & 0,0115 & 0,0165 & 0,0191 & 0,0255 \\
\hline M & 2 & $-0,2005$ & $-0,0038$ & 0,0150 & 0,0187 & 0,0243 & 0,0182 & 0,0196 & 0,0164 & 0,0151 & 0,0120 & 0,0160 & 0,0158 & 0,0174 & 0,0137 \\
\hline $\mathrm{N}$ & 1 & $-1,0826$ & $-0,0144$ & $-0,0011$ & 0,0133 & 0,0168 & 0,0092 & 0,0166 & 0,0126 & 0,0112 & 0,0045 & 0,0052 & 0,0042 & 0,0028 & $-0,0221$ \\
\hline 0 & 1 & 0,0233 & 0,0003 & 0,0120 & 0,0117 & 0,0176 & 0,0072 & 0,0119 & 0,0110 & 0,0107 & 0,0131 & 0,0124 & 0,0129 & 0,0110 & 0,0105 \\
\hline $\mathbf{P}$ & 1 & $-10,3395$ & $-0,0407$ & $-0,0368$ & 0,0039 & 0,0019 & 0,0019 & 0,0049 & 0,0041 & 0,0069 & 0,0027 & 0,0024 & $-0,0076$ & $-0,0624$ & $-0,1190$ \\
\hline R & 2 & $-0,2262$ & $-0,0031$ & 0,0105 & 0,0136 & 0,0180 & 0,0142 & 0,0127 & 0,0122 & 0,0108 & 0,0103 & 0,0098 & 0,0112 & 0,0138 & 0,0075 \\
\hline$s$ & 1 & $-0,4053$ & $-0,0080$ & 0,0118 & 0,0199 & 0,0276 & 0,0191 & 0,0165 & 0,0236 & 0,0124 & 0,0093 & 0,0124 & 0,0131 & 0,0145 & 0,0098 \\
\hline$T$ & 1 & $.0,0760$ & $\cdot 0,0014$ & 0,0171 & 0,0185 & 0,0269 & 0,0135 & 0,0164 & 0,0180 & 0,0178 & 0,0188 & 0,0199 & 0,0200 & 0,0164 & 0,0104 \\
\hline MEAN & & $-0,3682$ & $-0,0049$ & 0,0084 & $0,0133^{\prime \prime}$ & $0,0169^{\prime}$ & 0,0132 & $0,0144^{r}$ & $0,0113^{r}$ & $0,0107^{\prime}$ & $0,0080^{\prime}$ & $0,0098^{\prime \prime}$ & $0,0117^{\prime}$ & $0,0092^{\prime}$ & 0,0033 \\
\hline
\end{tabular}

Table 1: The ROAs, their changings, and the leap periods (when the starting intensity of the new HRM practices are increased) with the industrial mean.

The analyze is based on the comparing of two periods ( 1 and 2$)$ and the results are limited with the comparing of these two periods. The banks A, B, C, D, F, H, I, K, L, M, N, P, R, S have the better compared ROA when they start new HRM practices; therefore, they are the supporters of the hypothesis. The banks with the dark gray ground in their leap column, are the ones who have better relative performance in a period where the newer HRM practices' starting is relatively weak (banks E, G, J, O, T). It means that they are not familiar with the hypothesis of this paper. Since it is not an ordinary method, it could be better to clarify it with some of examples:

The Bank A has a lower compared ROA performance in the second period (2015-2019) and its leap period is the first one (2010-2014). Since the compared ROA is higher than the mean in the first period and the most of the newer HRM practices exist at the same period; the Bank A is accepted as one of the supporters of the hypothesis.

Likewise, Bank B has a better compared ROA in the second period when the most of new HRM practices begin. Since the compared ROA is higher than the mean in the second period and the most of the newer HRM practices exist in the second period too; the Bank B is also accepted as one of the supporters of the hypothesis.

Inversely, Bank $\mathrm{E}$ has a better compared ROA in the second period while the most of new HRM practices begin in the first period. Since the compared ROA is higher than the mean in the second period while the most of the newer HRM practices start in the first period; the Bank E is not accepted as one of the supporters of the hypothesis.

And Bank J, has a worse compared ROA in the second period while the most of new HRM practices begin in the second period. Since the compared ROA is lower than the mean in the second period while the most of the newer HRM practices start in the second period; the Bank $\mathrm{J}$ is not accepted as one of the supporters of the hypothesis.

In sum, the ones who have the higher relative ROA average and intensive HRM practices' starting in mean period are the supports of the hypothesis, and they have white grounds; while the ones, whose higher relative ROA average and intensive HRM practices' starting exist in the different periods, are the non-supporters, and they have gray ground.

The leap period might consist to one year, two years or even three or four years. However, clearest results are founded in the five years periods. It means that, most significant $(\mathrm{p}=0.027)$ relation between relative ROA average and leap period was found with the five years period. That's why the leap periods are stated as the 5 years.

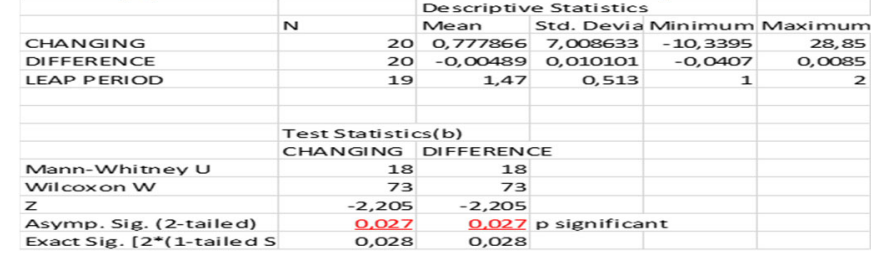

Table 2: Statistical results of leap period and ROA comparing

Since the most of the banks in the sector supports the hypothesis, it possible to say that the hypothesis is confirmed. Although this relationship is clearly viewed on the table 2, the "Mann-Whitney U" analysis is carried out in order to display it statistically. The result is significant (see in Table 2).

On the other hand, this result reflects the co-variation also, within the limits of the study's analyze. Because it is clearly seen that the most of the banks have a worse (compared) performance when they have not many HRM practices' starting. It means that the relative performance is failed when the period cannot be accepted as the leap period.

\subsection{About the causality}

In order to find the causality relation, that is to say, to understand whether the banks turn towards the HRM or not 
after their lower compared ROA year, I have analyzed the lower compared ROA years of the banks and the intensity of their HRM practices' in subsequent year(s).

This time, the HRM reaction of the banks are questioned and it is analyzed whether the banks start a new leap period or not, after their weak performance year(s). If most of the banks starts a new leap period after their weak performance year(s) it means that they expect to contribute to the firm performance by triggering a new HRM movement. So, if it is confirmed, it means that there is the causality relation between HRM and firm performance beyond the synchronic relation. In this frame, firstly the changings of compared ROA of each bank should be seen in Table 3. The "darker" cells show the lower ROA years of each bank. It is good for understanding to see the causality relation to these lower ROA years as well as their subsequences with the Table 4 in where the lower ROA's and the banks' HR reactions exist.

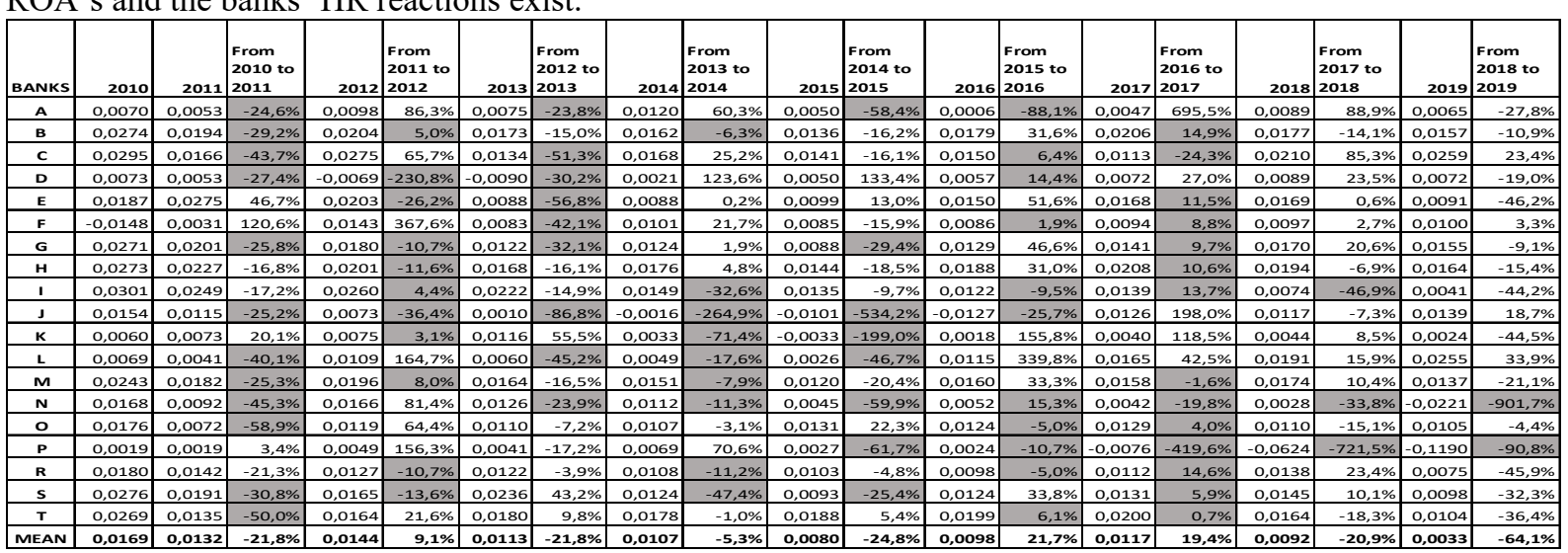

Table 3: ROA changings of the banks, year by year.

It is proposed here that the firm (the bank) who expects the HRM contributes to the performance (ROA), would increase its new HRM practices as a reaction to their lower performance(s). Then if the quantity of the subsequent years where the new HRM practices are higher after the lower ROA; it is considered that the analyzed bank has bias to use the HRM in order to improve the performance. Table 4 (below) shows the lower ROA years of the banks and the banks' reactions against the lower ROA. If the bank increases its new HRM practices the cell stays with light ground. If the bank does not increase the newer HRM practices after the lower ROA, the cell is signed with the dark gray ground. If the quantity of light grounds is higher than the dark grounds it means that it does support the P1. If not, it does not support the P1.

\begin{tabular}{|c|c|c|c|c|c|c|c|c|c|c|}
\hline & & \multicolumn{9}{|c|}{ YEARS } \\
\hline Banks & $\begin{array}{l}\text { Tower ROA } \\
\text { years }\end{array}$ & 2011 & 2012 & 2013 & 2014 & 2015 & 2016 & 2017 & 2018 & SUPPORT \\
\hline A & $\begin{array}{l}\text { 2011, 2013, } \\
\text { 2015, 2016 }\end{array}$ & $2012 \mathrm{HR}>2011 \mathrm{HR}$ & & $2014 \mathrm{HR}>2013 \mathrm{HR}$ & & $2016 \mathrm{HR}>2015 \mathrm{HR}$ & $2017 \mathrm{HR}>2016 \mathrm{HR}$ & & & SUPPORTS \\
\hline B & $\begin{array}{l}2011,2012, \\
2014,2017\end{array}$ & $2012 \mathrm{HR}>2011 \mathrm{HR}$ & $2013 \mathrm{HR}>2012 \mathrm{HR}$ & & $2015 \mathrm{HR}>2014 \mathrm{HR}$ & & & $2018 \mathrm{HR}<2017 \mathrm{HR}$ & & SUPPORTS \\
\hline C & $\begin{array}{l}\text { 2011, 2013, } \\
\text { 2016, 2017 }\end{array}$ & $2012 \mathrm{HR}>2011 \mathrm{HR}$ & & $2014 \mathrm{HR}>2013 \mathrm{HR}$ & & & $2017 \mathrm{HR}>2016 \mathrm{HR}$ & $2018 \mathrm{HR}>2017 \mathrm{HR}$ & & SUPPORTS \\
\hline D & \begin{tabular}{|l|}
2011,2012, \\
2013,2016
\end{tabular} & $2012 \mathrm{HR}>2011 \mathrm{HR}$ & $2013 \mathrm{HR}=2012 \mathrm{HR}$ & $2014 \mathrm{HR}<2013 \mathrm{HR}$ & & & $2017 \mathrm{HR}>2016 \mathrm{HR}$ & & & \\
\hline E & $2012,2013,2017$ & & $2013 \mathrm{HR}>2012 \mathrm{HR}$ & $2014 \mathrm{HR}<2013 \mathrm{HR}$ & & & & $2018 \mathrm{HR}<2017 \mathrm{HR}$ & & $\begin{array}{l}\text { DOES NOT } \\
\text { SUPPORT }\end{array}$ \\
\hline $\mathbf{F}$ & $2013,2016,2017$ & & & $2014 \mathrm{HR}=2013 \mathrm{HR}$ & & & $2017 \mathrm{HR}>2016 \mathrm{HR}$ & $2018 \mathrm{HR}>2017 \mathrm{HR}$ & & SUPPORTS \\
\hline G & \begin{tabular}{|l|}
2011,2012, \\
$2013,2015,2017$
\end{tabular} & $2012 \mathrm{HR}<2011 \mathrm{HR}$ & $2013 H R>2012 H R$ & $2014 \mathrm{HR}<2013 \mathrm{HR}$ & & $2016 \mathrm{HR}<2015 \mathrm{HR}$ & & $2018 \mathrm{HR}<2017 \mathrm{HR}$ & & \begin{tabular}{|l} 
DOES NOT \\
SUPPORT \\
\end{tabular} \\
\hline $\mathbf{H}$ & 2012,2017 & & $2013 \mathrm{HR}>2012 \mathrm{HR}$ & & & & & $2018 \mathrm{HR}<2017 \mathrm{HR}$ & & \\
\hline 1 & \begin{tabular}{|l|}
2012,2014, \\
$2016,2017,2018$
\end{tabular} & & $2013 \mathrm{HR}=2012 \mathrm{HR}$ & & $2015 \mathrm{HR}=2014 \mathrm{HR}$ & & $2017 \mathrm{HR}<2016 \mathrm{HR}$ & $2018 \mathrm{HR}<2017 \mathrm{HR}$ & $2019 \mathrm{HR}>2018 \mathrm{HR}$ & $\begin{array}{l}\text { DOES NOT } \\
\text { SUPPORT }\end{array}$ \\
\hline J & \begin{tabular}{|l|}
2011,2012 \\
2013,2014 \\
2015,2016 \\
\end{tabular} & $2012 \mathrm{HR}>2011 \mathrm{HR}$ & $2013 \mathrm{HR}<2012 \mathrm{HR}$ & $2014 \mathrm{HR}>2013 \mathrm{HR}$ & $2015 \mathrm{HR}>2014 \mathrm{HR}$ & $2016 \mathrm{HR}<2015 \mathrm{HR}$ & $2017 \mathrm{HR}>2016 \mathrm{HR}$ & & & SUPPORTS \\
\hline K & $2012,2014,2015$ & & $2013 \mathrm{HR}<2012 \mathrm{HR}$ & & $2015 \mathrm{HR}<2014 \mathrm{HR}$ & $2016 \mathrm{HR}=2015 \mathrm{HR}$ & & & & $\begin{array}{l}\text { DOES NOT } \\
\text { SUPPORT } \\
\end{array}$ \\
\hline $\mathbf{L}$ & \begin{tabular}{|l|}
2011,2013 \\
2014,2015 \\
\end{tabular} & $2012 \mathrm{HR}>2011 \mathrm{HR}$ & & $2014 \mathrm{HR}<2013 \mathrm{HR}$ & $2015 \mathrm{HR}>2014 \mathrm{HR}$ & $2016 \mathrm{HR}>2015 \mathrm{HR}$ & & & & SUPPORTS \\
\hline M & \begin{tabular}{|l|}
2011,2012 \\
2014, 2017 \\
\end{tabular} & $2012 \mathrm{HR}=2011 \mathrm{HR}$ & $2013 \mathrm{HR}<2012 \mathrm{HR}$ & & $2015 \mathrm{HR}>2014 \mathrm{HR}$ & & & $2018 \mathrm{HR}<2017 \mathrm{HR}$ & & \begin{tabular}{|l} 
DOES NOT \\
SUPPORT \\
\end{tabular} \\
\hline $\mathbf{N}$ & \begin{tabular}{|l|}
2011,2013, \\
2014,2015, \\
$2017,2018,2019$ \\
\end{tabular} & $2012 \mathrm{HR}=2011 \mathrm{HR}$ & & $2014 \mathrm{HR}<2013 \mathrm{HR}$ & $2015 \mathrm{HR}=2014 \mathrm{HR}$ & $2016 \mathrm{HR}=2015 \mathrm{HR}$ & & $2018 \mathrm{HR}>2017 \mathrm{HR}$ & $2019 \mathrm{HR}>2018 \mathrm{HR}$ & $\begin{array}{l}\text { DOES NOT } \\
\text { SUPPORT }\end{array}$ \\
\hline $\mathbf{0}$ & $2011,2016,2017$ & $2012 \mathrm{HR}>2011 \mathrm{HR}$ & & & & & $2017 \mathrm{HR}=2016 \mathrm{HR}$ & $2018 \mathrm{HR}>2017 \mathrm{HR}$ & & SUPPORTS \\
\hline $\mathbf{P}$ & \begin{tabular}{|l|}
2015,2016, \\
$2017,2018,2019$ \\
\end{tabular} & & & & & $2016 \mathrm{HR}<2015 \mathrm{HR}$ & $2017 \mathrm{HR}=2016 \mathrm{HR}$ & $2018 \mathrm{HR}>2017 \mathrm{HR}$ & $2019 \mathrm{HR}>2018 \mathrm{HR}$ & \\
\hline $\mathbf{R}$ & \begin{tabular}{|l|}
2012,2014 \\
2016,2017 \\
\end{tabular} & & $2013 \mathrm{HR}=2012 \mathrm{HR}$ & & $2015 \mathrm{HR}>2014 \mathrm{HR}$ & & $2017 \mathrm{HR}>2016 \mathrm{HR}$ & $2018 \mathrm{HR}>2017 \mathrm{HR}$ & & SUPPORTS \\
\hline $\mathbf{s}$ & \begin{tabular}{|l|}
2011,2012, \\
$2014,2015,2017$ \\
\end{tabular} & $2012 \mathrm{HR}>2011 \mathrm{HR}$ & $2013 \mathrm{HR}>2012 \mathrm{HR}$ & & $2015 \mathrm{HR}<2014 \mathrm{HR}$ & $2016 \mathrm{HR}<2015 \mathrm{HR}$ & & $2018 \mathrm{HR}>2017 \mathrm{HR}$ & & SUPPORTS \\
\hline $\mathbf{T}$ & $2011,2016,2017$ & $2012 \mathrm{HR}>2011 \mathrm{HR}$ & & & & & $2017 \mathrm{HR}>2016 \mathrm{HR}$ & $2018 \mathrm{HR}>2017 \mathrm{HR}$ & & SUPPORTS \\
\hline
\end{tabular}

Table 4: The banks, their lower ROA years, and their (HRM) reactions to these lower ROA years.

Either the quantity of the supporter banks or of the supporter years. support the P1. Most of banks increases to start the newer HRM practices after their lower ROA year. And during the most of subsequent years of the lower years, the banks are increased their newer HRM practices. 
Since the quantity of the banks who increase intensively new HRM practices after the lower ROA year(s) more than the others, I argue that the banks expect and increase the HRM (practices) to improve the performance. And if it is unified with the confirmed H1, we can say that the banks expect the positive impact of the HRM on the firm performance and there is a positive relation between the HRM and the performance. We can say that the HRM is one of the factors who improve the financial performance.

But the analyzes don't stop with these results. In search of common characteristic(s) of the supporter and nonsupporter banks, another interesting result is faced. With the reference of an older study, I analyze this relationship by looking the personnel expenses per employee.

\begin{tabular}{|c|c|c|c|c|c|c|c|c|c|c|c|c|c|}
\hline $\begin{array}{l}\text { Personnel expenses } \\
\text { (per employee) }\end{array}$ & $\begin{array}{l}\text { Average of second } \\
\text { period (2015-19) }\end{array}$ & 2019 & 2018 & 2017 & 2016 & 2015 & $\begin{array}{l}\text { Personnel expenses } \\
\text { (per employee) }\end{array}$ & $\begin{array}{l}\text { Average of first } \\
\text { period (2010-14) }\end{array}$ & 2014 & 2013 & 2012 & 2011 & 2010 \\
\hline K & \begin{tabular}{|l|l|}
187,04 \\
\end{tabular} & 290,3 & 229 & 160,6 & 139,5 & 115,8 & D & 108,02 & 134 & 119,5 & 102,5 & 100,6 & 83,5 \\
\hline A & 185,94 & 218,1 & 203,3 & 173,2 & 170,8 & 164,3 & M & 101,52 & 123 & 113,7 & 103 & 87,4 & 80,5 \\
\hline D & 185,74 & 225,4 & 192,1 & 178,8 & 174 & 158,4 & A & 98,96 & 134,9 & 103,4 & 99,5 & 83,6 & 73,4 \\
\hline $\mathrm{J}$ & 184,38 & 244,2 & 203,6 & 178,6 & 177,9 & 117,6 & $\mathbf{P}$ & 97,94 & 112 & 114,7 & 98 & 87 & 78 \\
\hline $\mathbf{P}$ & 178,74 & 248,4 & 197,3 & 186,9 & 131,1 & 130 & H & 85,74 & 101,3 & 89,5 & 87,4 & 80,7 & 69,8 \\
\hline H & 169,84 & 223 & 198,8 & 170,1 & 146,3 & 111 & $\mathrm{~J}$ & 85,22 & 108 & 97,6 & 83 & 73,3 & 64,2 \\
\hline M & 165,98 & 221,3 & 185,5 & 167,4 & 147 & 108,7 & $\mathrm{~F}$ & 83,92 & 92,8 & 73,5 & 90,2 & 79,2 & 83,9 \\
\hline B & 151,16 & 216,3 & 169,2 & 133,9 & 123 & 113,4 & s & 80,7 & 89,5 & 84,8 & 83,9 & 76,6 & 68,7 \\
\hline$s$ & 149,54 & 204 & 173,6 & 145,2 & 126,5 & 98,4 & K & 79,94 & 93,4 & 85,3 & 82,9 & 72,3 & 65,8 \\
\hline c & 138,18 & 178,9 & 157,4 & 135,7 & 121 & 97,9 & L & 78,3 & 84,7 & 83,8 & 82,1 & 76,7 & 64,2 \\
\hline L & 137,2 & 198,8 & 144 & 127,7 & 113,3 & 102,2 & c & 75,92 & 100,3 & 81,9 & 72,1 & 65,3 & 60 \\
\hline $\mathbf{R}$ & 130,42 & 186,6 & 146,3 & 123 & 106,6 & 89,6 & B & 72,8 & 88 & 84,9 & 71,3 & 62,6 & 57,2 \\
\hline $\mathrm{F}$ & 127,74 & 169,7 & 146,2 & 123,4 & 101,9 & 97,5 & $\mathbf{R}$ & 70,3 & 82,6 & 74,4 & 64,6 & 68,2 & 61,7 \\
\hline 0 & 123,82 & 164,1 & 134 & 119,7 & 111,1 & 90,2 & 0 & 68,72 & 81,3 & 72,5 & 67 & 60,7 & 62,1 \\
\hline 1 & 123,76 & 159,7 & 138,9 & 120,7 & 110,6 & 88,9 & $\mathrm{~N}$ & 68,54 & 76,6 & 67,5 & 68,9 & 64,6 & 65,1 \\
\hline$N$ & 119,1 & 167,6 & 131,1 & 113,5 & 106,8 & 76,5 & $T$ & 63,2 & 77,1 & 71,6 & 59 & 53,9 & 54,4 \\
\hline$T$ & 115,66 & 155,9 & 129,3 & 112,1 & 100,4 & 80,6 & G & 62,6 & 73,4 & 64,8 & 62,4 & 62,1 & 50,3 \\
\hline G & 112,94 & 151,2 & 123,9 & 107,7 & 101,4 & 80,5 & I & 61 & 72,1 & 73,2 & 56,3 & 53,6 & 49,8 \\
\hline E & 103,128 & 132,2 & 114,8 & 103,1 & 91,64 & 73,9 & E & 56,84 & 67,4 & 57,5 & 55,9 & 55,3 & 48,1 \\
\hline
\end{tabular}

Table 5: Personnel expenses by years and by the periods with the highlighted non-supporter banks for the hypothesis.

As it is seen table 5, either in first period (2010-14) or in second period (2015-19) the four of the "five nonsupporters" exist among the banks whose personnel expenses are the lowest. They are the Banks O, T, G and E. It means that the most of the banks whose personnel expenses are lowest, cannot not change their ROA when they manage an HRM leap period. Or, the banks whose personnel expenses are lower, cannot change the ROA by carrying out an HRM leap period.

Personnel expenses contain the wages (salaries, bonuses, social security payments) as well as the cost of all HRM activities. Nevertheless, it is impossible to think that these expenses display the effectiveness of the HRM activities since there are much more factors who have the potential to change the effectiveness of them.

Hence, it is impossible to consider those "findings" as a result, it is just a "sign" who give a direction for further research to understand the HRM-performance relation.

And the same analyze is re-done for the causality impact. Concerning the P1, there were six non-supporter banks. Four of them (Banks E, G, N, I) are still among the ones whose personnel expenses are lower. And it is still important as a sign for further researches.

\begin{tabular}{|c|c|c|c|c|c|c|c|c|c|c|c|c|c|}
\hline $\begin{array}{l}\text { Personnel expenses } \\
\text { (per employee) }\end{array}$ & $\begin{array}{l}\text { Average of second } \\
\text { period (2015-19) }\end{array}$ & 2019 & 2018 & 2017 & 2016 & 2015 & $\begin{array}{l}\text { Personnel expenses } \\
\text { (per employee) }\end{array}$ & $\begin{array}{l}\text { Average of first } \\
\text { period (2010-14) }\end{array}$ & 2014 & 2013 & 2012 & 2011 & 2010 \\
\hline K & 187,04 & 290,3 & 229 & 160,6 & 139,5 & 115,8 & D & 108,02 & 134 & 119,5 & 102,5 & 100,6 & 83,5 \\
\hline A & 185,94 & 218,1 & 203,3 & 173,2 & 170,8 & 164,3 & M & 101,52 & 123 & 113,7 & 103 & 87,4 & 80,5 \\
\hline D & 185,74 & 225,4 & 192,1 & 178,8 & 174 & 158,4 & A & 98,96 & 134,9 & 103,4 & 99,5 & 83,6 & 73,4 \\
\hline J & 184,38 & 244,2 & 203,6 & 178,6 & 177,9 & 117,6 & $\mathbf{P}$ & 97,94 & 112 & 114,7 & 98 & 87 & 78 \\
\hline $\mathbf{P}$ & 178,74 & 248,4 & 197,3 & 186,9 & 131,1 & 130 & H & 85,74 & 101,3 & 89,5 & 87,4 & 80,7 & 69,8 \\
\hline H & 169,84 & 223 & 198,8 & 170,1 & 146,3 & 111 & $\mathrm{~J}$ & 85,22 & 108 & 97,6 & 83 & 73,3 & 64,2 \\
\hline M & 165,98 & 221,3 & 185,5 & 167,4 & 147 & 108,7 & $\mathbf{F}$ & 83,92 & 92,8 & 73,5 & 90,2 & 79,2 & 83,9 \\
\hline B & 151,16 & 216,3 & 169,2 & 133,9 & 123 & 113,4 & $\mathrm{~s}$ & 80,7 & 89,5 & 84,8 & 83,9 & 76,6 & 68,7 \\
\hline$s$ & 149,54 & 204 & 173,6 & 145,2 & 126,5 & 98,4 & $\mathrm{~K}$ & 79,94 & 93,4 & 85,3 & 82,9 & 72,3 & 65,8 \\
\hline c & 138,18 & 178,9 & 157,4 & 135,7 & 121 & 97,9 & L & 78,3 & 84,7 & 83,8 & 82,1 & 76,7 & 64,2 \\
\hline L & 137,2 & 198,8 & 144 & 127,7 & 113,3 & 102,2 & c & 75,92 & 100,3 & 81,9 & 72,1 & 65,3 & 60 \\
\hline R & 130,42 & 186,6 & 146,3 & 123 & 106,6 & 89,6 & B & 72,8 & 88 & 84,9 & 71,3 & 62,6 & 57,2 \\
\hline F & 127,74 & 169,7 & 146,2 & 123,4 & 101,9 & 97,5 & $\mathbf{R}$ & 70,3 & 82,6 & 74,4 & 64,6 & 68,2 & 61,7 \\
\hline 0 & 123,82 & 164,1 & 134 & 119,7 & 111,1 & 90,2 & 0 & 68,72 & 81,3 & 72,5 & 67 & 60,7 & 62,1 \\
\hline 1 & 123,76 & 159,7 & 138,9 & 120,7 & 110,6 & 88,9 & $\mathrm{~N}$ & 68,54 & 76,6 & 67,5 & 68,9 & 64,6 & 65,1 \\
\hline N & 119,1 & 167,6 & 131,1 & 113,5 & 106,8 & 76,5 & $T$ & 63,2 & 77,1 & 71,6 & 59 & 53,9 & 54,4 \\
\hline$T$ & 115,66 & 155,9 & 129,3 & 112,1 & 100,4 & 80,6 & G & 62,6 & 73,4 & 64,8 & 62,4 & 62,1 & 50,3 \\
\hline G & 112,94 & 151,2 & 123,9 & 107,7 & 101,4 & 80,5 & 1 & 61 & 72,1 & 73,2 & 56,3 & 53,6 & 49,8 \\
\hline E & 103,128 & 132,2 & 114,8 & 103,1 & 91,64 & 73,9 & E & 56,84 & 67,4 & 57,5 & 55,9 & 55,3 & 48,1 \\
\hline
\end{tabular}

Table 6: Personnel expenses by years and by the periods with the highlighted non-supporter banks for the proposition

\section{Discussion}

First, let's summarize what is enlighten: When the banks have an HRM leap period, their financial performance (ROA) is higher than the industrial performance average. When they have not a such HRM leap, their compared financial performance is lower.

Further, when they face a financial performance problem (ROA), they increase their newer HRM practices' starting during the subsequent period. Each time, the financial performance does not improve after the intensity of 
HRM practices, they nevertheless do it. Because they expect to improve their financial performance by intensifying their HRM practices. And since the HRM is not the unique factor that can contribute to profitability, the starting of HRM practices as the reaction of a relative lower ROA year, cannot guaranty the performance improving.

Those are what this paper argues. And what are the ones that this paper could not argue?

First, why that's the leap period but not the HRM practices that ensures the profitability? Most logical answer of this question concerns a different variable that make the HRM impact be "tangible". It may be the impact of HRM on the employees' perceptions (Truss, 2001:1143-1146; Dysvik \& Kuvaas, 2008); employees may be influenced by the intensity of the HRM practices as well as the other managerial activities in a limited period. Or, it may be another different variable that transforms the HRM impact into the performance.

Secondly, the strategic dimension of the HRM practices, is still a "mystery". There should be a conformity between the HRM practices and the firm strategy, that contributes the firm performance, but it was not possible to figure out this dimension with the annuals, since the strategies were not clearly mentioned like the newer HRM practicese.

Third, the institutionalization impact could not be discovered in this paper either. In fact, it seems like the new institutionalization is also acceptable based on the results of this paper. Because any significant impact is not seen between a newer HRM practice and the firm performance, but the "bundles of the leap periods" affects the performance. In fact, it means that its not the HRM practices one by one, but the "synergy" that consists of the HRM leap improves the performance.

Hence, maybe, the HRM practices and techniques are chosen by the effect of the (new) institutionalization, without being sure whether it will improve the performance or not, but their impact is real when they are applicated as a body.

And lastly, I did not see any clustering that consists of the ownership or of the size. Bank I, R and $\mathrm{T}$ are the ones whose owner is the public. Almost all banks have foreigner partners. Only Bank B, C, M, are the ones are private banks and their owners have Turkish nationality. Bank $\mathrm{J}$ and $\mathrm{P}$ are the ones founded by a big international group. And the others international partners penetrated into the market by acquisitions. Their penetrating period is between 2005-15 (generally). But the partnership levels are different and unstable. There are some banks who acquired twice in ten years.

About the size: the banks A, C, D, F, J K, L, N and P are the smaller banks. They are the smalls banks in Turkey but the holder groups of these banks are big. In any case I did not see any clustering either, concerning the size of the banks.

Honestly, it was not surprising for me because the HRM practices (newer or not) so extensively applicated that the any bank could ignore them. Yet the impact of the HRM practices cannot guaranty the performant impact. There should be some different factor(s), such a leap that consist of an intensive application of managerial as well as HRM activities, or contingency that consists of the compliance with the organizational strategy or any other factor that cannot be recognized here.

\section{Limitations:}

Is the ROA considered as the best indicator for the performance? Even we can ask whether the financial performance is the best indicator of the firm performance or not. Not only financial ones but all performance criteria can be disputable upon the context. But the financial ones, particularly the profitability, are less disputable. And what about the reliability of the annuals? The annuals, particularly the ones of the banks, are strictly controlled. But moreover, the annuals are more trustable concerning the newer HRM practices, because, starting the newer HRM practices confirms to stakeholders, that the HR department works and actualizes the practices. So, the banks are proud of practicing the contemporary management technics and they don't hide their novelties, actions.

Might the effectiveness of the HRM practices influence the results? Unfortunately, it is impossible to measure the effectiveness of the HRM practice by analyzing the annuals. It is fatal to address the respondents' (employees here) perceptions to measure the effectiveness of the HRM practices. But it is clear that the effectiveness of the HRM practices cannot be measured merely with the surveys on the employees' perceptions. There should be better ways to figure out the complex structure of the effectiveness. However, the works concerning the personnel expenses may be a simple sign. If it is considered as a sign it possible to say that the relation between HRM and firm performance would be more significant when the effectiveness of the HRM are taken into account.

\section{For the future}

Very shortly, there are three fields to develop the research concerning the SHRM: The institutionalization impact is one of them. It is clear that the all HRM practices are not driven with the performance expectation, even though they may improve it. When the reason is the performance, when the reason is the social or the reglementary press or when it consists of the common culture and shared values; they are the questions should be analyzed. Among

\footnotetext{
- Although the banks officially mentioned their strategy, it was clear that the strategies were much more complexes than the mentioned ones.
} 
those questions the ones concerning the rules and laws are less noteworthy, at least for SHRM, because their isomorphic effect is evident. Further researches may focus the social press and shared values.

On the other hand, contingency dimension is another field to analyze. Since the impact of the HRM practices bundles is higher, it is more persuasive that they are driven with a coordination that cannot be exist without a decisive and planned (higher) managerial action. It means that those bundles cannot be run without a strategy. But the strategy as a concept may have a different form relatively what we know (Boon, Boselie, Paauwe \& Hartog, 2007). Maybe the obsoleteness of the strategy concept and/or our insufficiency to figure out the strategic management mechanism should be discussed.

Thirdly and classically, further researches may look into the "black box". How the HRM practices transform to the profit increasing. Based on the papers of last 20 years as well as this one, it is possible to say that the black box has, at least, two different parts: first HRM practices change something with the employees (their perception on the organization, on the managers etc. or their adaptation with organizational goals or simply their motivation or may be their entrepreneur competencies (Vu \& Nwachukwu, 2021). Then, secondly, the "changed employees" do something different and improve the organizational performance. Although the second part ensures the financial performance, it should be related with the operational performance that can take the different form upon the industry. It should be added that the analyzes with the black box cannot stop when its mechanism is unfolded; because it is seen in this paper that the SHRM cannot guaranty indefinite high performance; the way to make the black box be sustainable, should be found.

\section{References}

Arthur, J. (1992). The Link Between Business Strategy and Industrial Relations System in American Steel Minimills. Industrial and Labor Relations Review, 45(3), 488-506.

Arthur, J. (1994). Effects of Human Resource Systems on Manufacturing Performance and Turnover. Academy of Management Journal, 37(3), 670-687.

Bae, J. \& Lawler, J.J. (2000). Organizational and HRM Strategies in Korea: Impact on Firm Performance in an Emerging Economy. Academy of Management Journal, 43(3), 502-517.

Walk, M., Schinnenburg, H. \& Handy, F. (2013). Missing in Action: Strategic Human Resource Management in German Nonprofits. Voluntas, 25, 991-1021.

Barney, J.B. (1991). Firm Resources and Sustained Competitive Advantage. Journal of Management, 17(1), 99120.

Barney, J.B. \& Wright, P.M. (1998). On Becoming a Strategic Partner: The Role of Human Resources in Gaining Competitive Advantage. Human Resource Management, 37(1), 31-46.

Barrette, J. \& Carrière, J. (2003). La performance organisationnelle et la complémentarité des pratiques de gestion des ressources humaines. Relations Industrielles/Industrial Relations, 58(3), 427-453.

Boon, C., Boselie, P., Paauwe, J. \& Den Hartog, D. (2007). Academy of Management Annual Meeting Proceedings, (1), 1-6.

Bratton, J. \& Gold, J. (2007). Human Resource Management Theory and Practice. Palgrave-Macmillan, NY.

Carrière, J. \& Barette, J. (2005). Gestion des ressources humaines et performance de la firme à capital intellectuel élevé : une application des perspectives de contingence et de configuration. Canadian Journal of Administration Sciences/Revue canadienne des sciences de l'administration, 22(4), 302-315.

Chan, L.L.M., Shaffer, M.A. \& Snape, E. (2004). In Search of Sustained Competitive Advantage: The Impact of Organizational Culture, Competitive Strategy and Human Resource Management Practices on Firm Performance. International Journal of Human Resource Management, 15(1), 17-35.

Chow, I., Huang, J. \& Liu, S. (2008). Strategic HRM in China: Configurations and Competitive Advantage. Human Resource Management, 47(4), 687-706.

Çetintürk, I. (2017). Strategic Human Resource Management as Sustainable Competitive Advantage Source in Tourism Industries. Journal of Yasar University, 12(45), 48-59.

Deephouse, D.L. (1996). Does Isomorphism Legitimate? Academy of Management Journal, 39(4), 1024-1039.

Delaney, J. T., \& Huselid, M. A. (1996). The Impact of Human Resource Practices on Perceptions of Organizational Performance. Academy of Management Journal, 39(4), 949-969.

Devanna, M. A., Fombrun, C. J., \& Tichy, N. M. (1981). Human Resources Management: A Strategic Perspective. Organization Dynamics, Winter, 51-67.

Delery, J. E. (1998). Issues of Fit in Strategic Human Resource Management: Implications for Research. Human Resource Management Review, 8(3), 289-309.

Delery, J. E. \& Doty, H. E. (1996). Modes of Theorizing in Strategic Human Resource Management: Tests of Universalistic, Contingency, and Configurational Performance Predictions. Academy of Management Journal, $39(4), 802-835$

Dess, G., G. \& Davis, P., S. (1984). Porter's (1980) Generic Strategies as Determinants of Strategic Group Membership and Organizational Performance. Academy of Management Journal, 27(3), 467-488. 
DiMaggio P. J. \& Powell, W.W. (1983). The Iron Cage Revisited: Institutional Isomorphism and Collective Rationality in Organizational Fields. American Sociological Review, 48(2), 147-160.

Düzgün, A. \& Çetin, C. (2017). Stratejik İnsan Kaynakları Yönetimi ve Örgütsel Performans Arasındaki İlişkide Rekabet Stratejilerinin Aracı Etkisi: Antalya İli Örneği. Uluslararası Yönetim İktisat ve İşletme Dergisi/International Journal of Management Economics and Business, 17(Özel Say1/Special Issue), 498-511.

Dyer, L. \& Reeves, T. (1995). Human resource strategies and firm performance: what do we know and where do we need to go? The International Journal of Human Resource Management, 6(3), 656-670.

Dysvik, A. \& Kuvaas, B. (2008). The relationship between percieved training opportunities, work motivation, and employee outcomes. The Academy of Management Annual Meeting Proceedings 1, 1-6.

Festing, M. (2012). Strategic Human Resource Management in Germany: Evidence of Convergence to the U.S. Model, the European Model, or a Distinctive National Model. Academy of Management Perspectives, 37-54.

Fox, S. \& McLeay, S. (1992). An Approach To Researching Managerial Labour Markets: HRM, Corporate Strategy and Financial Performance in UK Manufacturing. The International Journal of Human Resource Management, $3(3), 523-554$.

Gerhart, B. (2005). Human Resources and Business Performance: Findings, Unanswered Questions, and an Alternative Approach. Management Revue, 16(2), 174-185.

Golden, K.A. \& Ramanujam, V. (1985). Between a Dream and a Nightmare: On the Integration of the Human Resource Management and Strategic Business Planning Processes. Human Resource Management, 24(4), 429-452.

Gollan, P.J., Kalfa, S. \& Xu, Y. (2015). Strategic HRM and devolving HR to the line: Cochlear during the shift to lean manufacturing. Asia Pacific Journal of Human Resources, 53, 144-162.

Guest, D.E., Michie, J., Conway, N. \& Sheehan, M. (2003). British Journal of Industrial Relations, 41(2), 294-314.

Hannan, M. T. \& Freeman, J. (1977). The Population Ecology of Organizations. American Journal of Sociology, 82(5), 929-964.

Harel, G.H. \& Tzafrir, S.S. (1999). The Effect of Human Resource Management Practices on the Perceptions of Organizational and Market Performance of the Firm. Human Resource Management, 38(3), 185-200.

Huselid, M.A. (1995). The Impact of Human Resource Management Practices on Turnover, Productivity, and Corporate Financial Performance. Academy of Management Journal, 38(3), 635-672.

Huselid, M.A. \& Becker, B. (1997). The Impact of High-Performance Work Systems, Implementation Effectiveness, and Alignment With Strategy on Shareholder Wealth. Academy of Management Best Papers Proceedings, 144-148.

Huselid, M.A., Jackson, S.E. \& Schuler, R.S. (1997). Technical and Strategic Human Resource Management Effectiveness as Determinants of Firm Performance. Academy of Management Journal, 40(1), 171-188.

Hoskisson, R.E., Hitt, M.A., Pan, W.P. \& Yiu, D. (1999). Theory and research in strategic management: swings of a pendulum. Journal of Management, 25(3), 417-456.

Ichniowski, C., Shaw, K. \& Prennushi, G. (1997). The Effetcts of Human Resource Management Practices on Productivity: A Study of Steel Finishing Lines. The American Economic Review, 87(3), 291-313.

Kamoche, K. (1996). Strategic human resource management within a resource capability view of the firm. Journal of Management Studies, 33(2), 213-233.

Kılıçarslan, Ö. \& Marşap, A. (2018). Stratejik İnsan Kaynakları Yönetimi ve Örgütsel Bağlılığa Etkisi. International Journal of Labor Life and Social Policy, 1(2), 5-23.

Kim, Y.H., Kim, Y., Kim, A., Han, K. \& Lepak, D. (2018). High-performance work systems as a remedy for growing pains: evidence from South Korean organizations. Asia Pacific Journal of Human Resources, 56, 293-316.

Kramar, R. \& Parry, E. (2014). Strategic human resource management in the Asia Pacific region: similarities and differences? Asia Pacific Journal of Human Resources, 56, 293-316

Lee, J. \& Miller, D. (1999). People Matter: Commitment to Employees, Strategy and Perfomance, in Korean Firms. Strategic Management Journal, 20, 579-593.

Liang, X., Marler, J. H. \& Cui, Z. (2012). Strategic Human Resource Management in China: East Meets West. Academy of Management Perspectives, 55-70.

Matei, T. (2013). Conceptial Clarification of Strategic Human Resource Management and The Way It Is Implemented, SEA-Practical Application of Science, 1(1), 182-191.

Wright, P. M. \& McMahan, G.C. (1992). Theoretical Perspectives for Strategic Human Resource Management. Journal of Management, 18(2). 295-320.

Meyer, J.W. \& Rowan, B. (1977). Institutionalized Organizations: Formal Structures as Myth and Ceremony. American Journal of Sociology, 83(2). 340-363.

Miller, D. (1988). Relating Porter's Business Strategies to Environment and Structure: Analysis and Performance Implications. Academy of Management Journal, 31(2), 280-308.

Nayyar, P. R. (1993). On the measurement of competitive strategy: evidence from a large multiproduct U.S. firm. 
Academy of Management Journal, 36(6), 1652-1669.

Oliver, C. (1997). Sustainable Competitive Advantage: Combining Institutional and Resource-Based Views. Strategic Management Journal, 18(9). 697-713.

Panayotopoulou, L., Bourantas, D. \& Papalexandris, N. (2003). Strategic human resource management and its effects on firm performance: an implementation of the competing values framework. The International Journal of Human Resource Management, 14(4), 680-699.

Prahalad, C.K. \& Hamel, G. (1990). The core competence of the corporation. Harvard Business Review, 90(3), 79-91.

Rose, R.C. \& Kumar, N. (2006). The Influence of Organizational and Human Resource Management Strategies on Performance. Performance Improvement 45(4), 18-24.

Schuler, R.S. \& Jackson, S.E. (1987). Linking Competitive Strategies with Human Resource Management Practice. The Academy of Management Executive, 1(3). 207-219.

Schuler, R.S. \& Jackson, S.E. (2005). A Quarter Century Review of Human Resource Management in the U.S.: The Growth in Importance of The International Perspective. Management Review, 16(1), 11-35.

Snell, S. A. \& Dean, J.W. (1992). Integrated Manufacturing and Human Resource Management: A Human Capital Perspective. Academy of Management Journal, 35(3), 467-504.

Sun, L.Y., Aryee, S. \& Law, K. S. (2007). High-Performance Human Resource Practices, Citizenship Behavior, And Organizational Performance, A Relational Perspective. Academy of Management Journal, 50(3), 558577.

Takeuchi, N. (2009). How Japanese manufacturing firms align their human resource policies with business strategies: testing a contingency performance prediction in a Japanese context. The International Journal of Human Resource Management, 20(1), 34-56.

Truss, C. \& Gratton, L. (1994). Strategic human resource management: a conceptual approach. The International Journal of Human Resource Management, 5(3), 663-686.

Truss, C. (2001). Complexities and controversies in linking HRM with Organizational Outcomes. Journal of Management Studies, 38(8), 1121-1149.

Vu, H.M. \& Nwachukwu, C. (2021). Influence of entrepreneur competencies on profitability and employee satisfaction, International Journal of Management and Enterprise Development, 20(1), 1-16.

Way, S.A. \& Johnson, D.E. (2005). Theorizing about the impact of strategic human resource management. Human Resource Management Review, 15, 1-19.

Webel, J.D. \& DeMarie, S.M. (2005). Aligning strategic human resource management and person-environment fit. Human Resource Management Review 15, 247-262.

Widener, S. (2006). Associations between strategic resource importance and performance measure use: The impact on firm performance. Management Accounting Research, 17, 433-457.

Wu, Z. \& Salomon, R. (2016). Does imitation reduce the liability of foreignness? Linking distance, isomorphism, and performance. Strategic Management Journal, 37, 2441-2462.

Youndt, M.A., Snell, S.A., Dean, J. W. \& Lepak, D.W. (1996). Human Resource Management, Manufacturing Strategy, and Firm Performance. Academy of Management Journal, 39(4), 836-866.

\section{APPENDIX}

\section{Summary of Banks' Newer Human Resource Management Practices}

All data summarized below are gathered from the annual reports of the commercial banks in Turkish banking sector. They are only the "newer practices", it means they are the ones who started for the first time in the year mentioned.

A Bank and its new HRM practices with their starting year

During the first period (2010-2014)

In 2010: Internal communication portal is developed. The suggestions system is enhanced with the rewarding system for suggestions.

In 2011: New sales premiums come for the employees in branches. The individual performance evaluation results become the basis for the promotion decisions. Branch visits that aim to employee satisfaction have started $(50 \%$ of the branches are visited).

In 2012: An employee club is founded in order to improve the employee loyalty and motivation. In this club the employee will be able to do several activities such their hobbies and their social events. Another aim of this club is to improve the internal communication. On the other hand, there is a changing concerning with the performance evaluation: reaching level to objectives was the unique criterion of the performance evaluation and the competence-based evaluation is added. Moreover, the results of the performance evaluation start to be used also for the training and career management. A new competence evaluation measurement for all positions and job evaluation in the organization are carried out in 2012. 
In 2013: For the first time HRM constituted a new MT (Management Trainee) pool and special formation programs are prepared for them. Distance training begun. Orientation training and individual development programs are prepared. Individual Development Center is founded. Lastly, employee reference program is started. In the frame of this program employees' references are used for finding new candidates.

In 2014: First, there are many plans. Secondly talents management begins (some components have already begun). Internal mentoring in the talent management is highlighted. A new portal is developed in where the employees says their "thanks" to the colleagues. Performance evaluation system changes, the corporation results are added to the bonus system. The "best employee" group is constituted and a special training program is offered to them. Lastly a certificate program contract is signed with a university.

During the second period (2015-2019)

In 2015: The bank is sold and there is not an important "leap" concerning the HRM practices.

In 2016: An internal tv station is founded for the training broadcasting.

In 2017: A new reward comes. This reward is offered to the employees who achieve something quickly. It means a quick project or contribution success concerning the process development, client satisfaction etc. Secondly gift program begins. Gifts are offered to the employees who have new born, anniversary, birthday, marriage, etc. Thirdly a new guide is developed for new entries, HR newsletter has started, HR meeting have started (for listening the employee's problem and employee loyalty survey has started, all of them were for the first time.

In 2018: Strategy office is founded. Organization office is attached to the HR department. And corporate culture and internal communication targeted unit is founded.

In 2019: "The employee line" is founded. Its aim is to guide the employees for their private life. Data mining infrastructure is ready (working for data mining infrastructure begins in 2018)

It is not easy to assign a leap period for Bank A. Starting of new HRM practices are almost synchronic distributed. However, it can be considered that the leap period is the first period because: the leaps in second period are generally based on the plans and strategy. Only 2017 is an important for new HRM.

On the other hand, the lower compared ROAs are recorded in 2011, 2013, 2015 and 2016. If the reaction of the bank during the subsequent years of these "relatively bad" years:

Is the 2012's HRM starting intensity bigger than 2011's - Yes

Is the 2014's HRM starting intensity bigger than 2013's - Yes

Is the 2016's HRM starting intensity bigger than 2015's - Yes, smoothly

Is the 2017's HRM starting intensity bigger than the 2016's - Yes, clearly

Bank B and its new HRM practices with the starting years:

During the first period (2010-2014):

In 2010: A better internal communication is mentioned as the new target for HR. There is no any new beginning but some improvements such the improvement of employee satisfaction surveys, of internal training staff, of IT for the employees, of the distance training activities as well as on the job training activities.

In 2011: Six sigma begins.

In 2012: Creating of the corporate culture and its values is mentioned as the new target of the HRM. And innovation is mentioned as the target of the corporate culture. Further, innovation teams are organized in 2012.

In 2013: Efficiency oriented organization action is added as the new target of the HRM. A new "academy" is founded for the e-learning programs. Training programs (generally leadership programs) for managers (any level) are enhanced. Internal mentoring and internal coaching programs begin. Innovation newsletter (bulletin) begins and a new reward "suggestion of the month" comes.

In 2014: There is no any new HRM practice.

During the second period (2015-2019):

In 2015: "Take your risk smartly" and "improvement on working process" become new the goals of the corporate culture. Rewarding system changes, "management by objective is added into the reward system and rewarding the employees who found the good candidates to work begins. A new academy (of training) is opened (in another city). Evaluation center for the talent management is opened and first training activities begin. Sales trainings begin. HR works for the satisfaction of the internal trainer staff. And a new HR data base is established. 
In 2016: "The generation banking" is mentioned as the new goal of the HRM. In that frame HRM will aim to improve the staff for servicing to the clients in the new banking technology and a new LAB is opened for guiding the staff to be innovative. And a Dashboard for HR begins to work.

In 2017: Training programs are transformed to the games. "Carrier interviews" and "expectations from HR" meetings begin; the objective is to improve the employee loyalty. A new rewarding program "thanks between departments" begins. Further targets are added into the rewarding program such "risk orientation", "competences" and "target orientation".

In 2018: A new project is planned. That aims to prepare the staff for the new technology, particularly about the data mining and virtual intelligence. In meantime restoration works begin for the branches' building. With the new designs of the branches' buildings, it's aimed to have a technologic appearance. HR department prepare itself for the Y generation. A couple of rewards come: first "honest banking reward" for the employees who take in account the client's interests and second "the reward of group" for the employees who sell the products of other companies of the conglomerate.

In 2019: "Center of excellence" is founded. The objective is to hire the young candidates who have the potential concerning the robotic applications and virtual intelligence. Brand management activities begin. "Meetings in universities" events, "internship demos" and internal recruitment announcements begin. A new orientation program is prepared and the meetings with managers program begins.

Bank B, like Bank A, is a bank whose leap period cannot be assigned easily. However, it is possible to say that the second period is good to be the leap period, if it is compared with the other one.

On the other hand, the lower compared ROAs are recorded in 2011, 2012, 2014 and 2017. If the reaction of the bank during the subsequent years of these "relatively bad" years:

Is the 2012's HRM starting intensity bigger than 2011's - Yes

Is the 2013's HRM starting intensity bigger than 2013's - Yes, Is the 2015's HRM starting intensity bigger than 2016's - Yes, clearly

Is the 2018's HRM starting intensity bigger than the 2017's - Yes, clearly.

Bank $\mathrm{C}$ and its new HRM practices with their starting years.

During the first period (2010-2014):

In 2010: A new efficiency program (goal based) begins. It is a part of Balanced Score Card (BSC) program. And "norm staff" program begins.

In 2011: There is just one changing: "individuality" is highlighted about the carrier planning.

In 2012: A new application is activated that aims to measure the level of reaching the sales targets of branches' staff. In addition, all banking applications transferred to the mobiles and the tablets (it is not finish but it has begun in 2012).

In 2013: An academy (with 7 different faculties) is built for the training activities.

In 2014: Marketing responsible managers in branches begun to see their performance on the system. And the branch coach scorecard begins.

During the second period (2014-2019):

In 2015: Talent management begins. Objective based performance begins. E-learning activities begins.

In 2016: Digitalization is improved and business intelligence practices begin.

In 2017: A new training program begins: There are four changings 1) For the costumer representatives, it aims to guide the PME's for taking decision in their financial or managerial activities in long or short term. 2) All training programs become client satisfaction oriented. 3) New training programs come; their objective is to coach the staff for the next step of their carrier (in old ones the objective was only to coach staff for their current position). 4) Training catalogue is enhanced. Moreover, new HRM targets come such "sustainable grooving" and "profitability". Objective based performance appraisal is spread. And lastly, internal mentoring program begins.

In 2018: IT program for $H R$ is activated. And internal mentoring program is spread for different levels and positions.

In 2019: A new digital "platform" activated for the employees' suggestions. And the training unit in HR department become an independent department.

Bank C, like the first ones, is a bank whose leap period cannot be assigned easily. However, it is possible to say that the second period is good to be the leap period, not only the quantity of the newer HRM practices but also 
because of their content.

Bank C also supports P1. Because the worst years of ROA for the bank C, are 2011, 2013, 2016, 2017. Let's check the subsequent years of these years with the lowest compared ROA.

Is the 2012's HRM starting intensity bigger than 2011's - Yes, smoothly Is the 2014's HRM starting intensity bigger than 2013's - Yes, smoothly Is the 2017 's HRM starting intensity bigger than 2016's - Yes, clearly Is the 2018's HRM starting intensity bigger than the 2017's - No, clearly

\section{Bank D and its new HRM practices with their starting years.}

During the first period (2010-2014):

In 2010: Compensation and performance appraisal systems change. Competences are added into the performance evaluation system as the new performance criterion.

In 2011: There is no any new HRM practice.

In 2012: The bank is sold. Concerning the HRM, internal mentoring begins and social events clubs are founded.

In 2013: New projects begin about the talent development and performance management with the participation of top managers: E-learning begins.

In 2014: Corporate culture's objectives are presented to the staff.

During the second period (2014-2019):

In 2015: "Norm staff" program activated. Branch visits begin. And a new communication platform is activated in order to make it better.

In 2016: In fact, 2016 is the year of plans. Almost all newer HRM practices in 2017 and 2018 are planned in 2016. The unique changing it the publishing of a new internal journal.

In 2017: Brand management program is prepared. Special training programs for the managers are carried out: first "leadership for emotions" training program for the branch and department managers; second "come together with the experience" training program for the high potential staff. Moreover, executive MBA program opportunity is given to high potential staff.

In 2018: Brand management begins. A new "staff loyalty program" begins. A new training catalogue is prepared and offered. The new catalogue let the staff choose the training subject. And a new hobby-sharing program begins in where everyone shares the knowing about his/her hobby.

2019: The social events and cultural development meetings are increased.

Even it is still very "unclear", like the first ones, the second period of the Bank D is assigned as the leap period. Because either relative quantity or enhanced content of the newer HRM practices in Bank D are higher in the second period than the first one. In meantime compared ROA average is also higher in second period; so, we can say that the Bank D supports the hypothesis.

About the proposition, it is easily seen that, the bank D's ROA is always characterized by floating: So, there are many worse years with ROA, such 2011, 2012, 2013 and 2016. Let's check all:

Is the 2012's HRM starting intensity bigger than 2011's - Yes, clearly (although the bank is acquired at that time)

Is the 2013's HRM starting intensity bigger than 2012's - Discussable

Is the 2014's HRM starting intensity bigger than 2013's - No, clearly

Is the 2017 's HRM starting intensity bigger than the 2016's - Yes clearly.

$\underline{\text { Bank E and its new HRM practices with their starting years. }}$

During the first period (2010-2014):

In 2010: "Norm staff" program begins.

In 2011: Wage committee is founded and it restructures the wages. Reward system changes. Individual preferences begin to be seen in training programs. Development Center is founded. Hobby ateliers begin to work. And HR side of BSC is spread.

In 2012: HR practices begin to be seen in social media more than the precedent years. And leadership-oriented 
new training programs begin for the managers.

In 2013: Recruitment process is checked and digitalized. Interviews are transformed to the video-conferences. Promotion system is enlarged and the bonuses are increased. Leadership oriented training programs are spread.

In 2014: Unique new HR changing is the development of the digitalization works about the HRM.

During the second period (2015-2019);

In 2015: A new (comprehensive) survey comes. This survey aims to measure satisfaction of "the new beginners", "the ones who live the bank" and "the ones who were refused". And the bank agreed with two universities for the MBA programs for the bank's staff.

In 2016: A digital communication group is founded (in What's Up Appl.) for all staff. And "converse-mentoring" program begins.

In 2017: All HRM practices are transferred to the mobile side. A new employee suggestion system is activated. A new management trainee program is activated. Foreign language courses begin (in the bank). And nursing-home visiting activities begin (with the participation of voluntaries).

In 2018: Interviews with the candidates are transferred to the social media. Data mining works begin. And the training programs are changed and updated in order to support the strategic objectives of banks.

In 2019: There is no any newer HRM practice. The unique development is the continue of the digitalization works.

Since the newer HRM practices are concerned the wages, bonuses, rewards in the first period while they are concerned mostly the digitalization (but not the humans), I assigned the first period as the leap period of the Bank E. But the compared ROA average of the bank E is higher in second period. So, the Bank E does not support the hypothesis.

On the other hand, the Bank E does not support the proposition either. If the years, where the compared ROA is lower, are analyzed, it can be seen that the Bank E does not consider the HRM as a weapon against the profitability problem. The lower ROA years and the HRM reactions of the Bank E:

Is the 2013's HRM starting intensity bigger than 2012's - Yes, smoothly

Is the 2014's HRM starting intensity bigger than 2013's - No

Is the 2018's HRM starting intensity bigger than 2017's - No

Bank F and its new HRM practices with their starting years.

All period (2010-2019)

In 2010: There is no any newer HRM practice

In 2011: There is only one changing: the HRM will restructured

In 2012: In 2012 there is no any newer HRM.

In 2013, 2014, 2015 and 2016: Annuals have the same sentences concerning the HRM.

In 2017: Banking academy is founded (in the bank). Employee loyalty and internal client satisfaction surveys begin.

In 2018: Performance appraisal system is extended for taking in all employees and for synchronization the individual and organizational interests. A new orientation program begins. Wages are ameliorated. And internship program begins (normally I don't add the internship programs but here, the program aims to invite the employees' children).

In 2019: The changings concern the performance evaluation system: feed-back interviews begin and it is started that the objectives are designed with the participation of the employees.

Bank F supports keenly the hypothesis of our theory. There is an explosion of newer HRM practices starting in 2018. Generally, second period is better than the first period but the last years are clearer.

Likewise, the second period's average of compared ROA is higher than the first period's one.

What about the bank's reaction for the ROA problems: The worst ROA years of the Bank F, are 2013, 2016 and 2017:

Is the 2014's HRM starting intensity bigger than 2013's - No, Is the 2017's HRM starting intensity bigger than 2016's - Yes, smoothly Is the 2018's HRM starting intensity bigger than 2017's - Yes, clearly 
Bank F supports the proposition, too.

Bank $\mathrm{G}$ and its new HRM practices with their starting years.

During the first period (2010-2014):

In 2010: Six Sigma begins. The criteria concerning the competencies are added the recruiting process. There are some works concerning the revenues of the employees, job analysis and job evaluation are renewed. And lastly a survey is carried out to see the evaluations of the employees on the corporate culture.

In 2011: Internal mentoring and coaching begin. Strategic talent management begins. The 360degree performance evaluation system is extended for all levels. A new manager training program begins. The wages are renewed and a new rewarding program begins. That new program rewards to employee behaviors that are familiar with the organizational culture. And lastly an internal customer satisfaction survey is carried out.

In 2012: There is no any new HRM practice.

In 2013: Carrier management transforms to the carrier architecture. With this transformation it is aimed to strengthen the strategy of finding the candidates from internal sources and in meantime it is aimed to guide the $Y$ generation for their struggle for designing their own carrier. Compensation committee is organized and the wages are restructured by "taking in account the social and individual private life of the employees". And "Life Atelier" is founded where the employees find the "sale coupons" for events that contribute their personal and intellectual developments. And some little changings concerning the performance evaluation system criteria have been seen. In 2014: Carrier advising begins in where the face to face carrier talks exist. And many meetings aim to develop the internal communication.

During the second period (2015-2019):

In 2015: Some new contracts with several universities about the MBA programs, are signed. Technology is enhanced for the training programs. And the catalogues begin for the employees' individual choices. Brand management begins for the recruitment process. And the performance evaluation system is individualized.

In 2016: Some discount contracts are signed with the several companies, for the employees. A new reward comes that aims employees to stop their taking too much risk for gaining bonus. And some little changings concerning the performance evaluation system have been seen.

In 2017: There some works for the $Y$ and $Z$ generations' adaptation to bank and business life.

In 2018 and 2019: There is no any new HRM practice.

For the bank $\mathrm{G}$ the first period is the leap period. But the compared ROA average is higher in second period. Therefore, it cannot be said that the Bank G supports the hypothesis.

When the causality effect is checked in the Bank G's history, first, it can be seen that the bank's ROA has a floating character. 2011, 2012, 2013, 2015 and 2017 are the years when the compared ROA is lower. And how about the HRM reaction of bank, against ROA problem?

Is the 2012's HRM starting intensity bigger than 2011's - No, clearly

Is the 2013's HRM starting intensity bigger than 2012's - Yes, clearly

Is the 2014's HRM starting intensity bigger than 2013's - No, clearly

Is the 2016's HRM starting intensity bigger than 2015's - No

Is the 2018's HRM starting intensity bigger than the 2017's - No

Bank $\mathrm{G}$ does not support the proposition, either.

$\underline{\text { Bank } \mathrm{H} \text { and its new HRM practices with their starting years. }}$

During the first period (2010-2014):

In 2010: A new program begins that contains carrier management and performance appraisal in meantime.

In 2011: Talent management is modified. $Y$ generation and the women become the subjects of the HRM.

In 2012: Training programs become more client (satisfaction) oriented.

In 2013: Work-Private Life balance become the main subject of the HRM. (More) Individualism in training programs and the self-decision about the training subject begin. Internal coaching also begins in 2013.

In 2014: Online interviews with the candidates begin. Training materials are transferred the mobiles. And converse mentoring begins. 
During the second period (2015-2019):

In 2015: Salary bonuses begin to be paid every month (instead of every quarter). Leadership modelling is renewed for developing the human and business management. And employee reference program (for new candidates) begins.

In 2016: A new bonus system started for the branches and the regional headquarters. A new orientation program begins, the objective of the new program is the better presentation of the corporate culture to the new entries. A line against domestic violence is opened for the employees. And HeforShe (of UN) begins. In Bank $\mathrm{H}$.

In 2017: A new employee suggestion system is activated (particularly for the HRM practices). A new competency system activated that aims to supply the firm's strategy. For training system, academic model begins in which the training activities have the credits and the managers can see total the credits of their subordinates. Coaching system begins for carrier planning and advising systems. The performance evaluation system is modified in order to synchronize the individual and organization performance for rewarding.

In 2018: There is no important newer HRM practice.

In 2019: In the frame of work-private life program a new kind of "leave" begins that let the employees take a break in their work for a long time.

Although 2018, it is clear that the second period (2015-19) is the leap period for the Bank H. And the average of compared ROA is higher in the second period. Hence the Bank H supports the hypothesis.

On the other hand, the Bank $\mathrm{H}$ is excluded from the proposition testing. The lowest ROAs that are recorded in 2012 and 2017. Here are the reactions of the Bank H:

Is the 2013's HRM starting intensity bigger than 2012's - Yes, clearly.

Is the 2018's HRM starting intensity bigger than the 2017's - No, clearly.

It is impossible to use this data for evaluating the proposition then, the Bank $\mathrm{H}$ is excluded.

Bank I and its new HRM practices with their starting years.

During the first period (2010-2014):

In 2010: There is only one changing: the HRM practices become familiar with the public regulations.

In 2011: First, the individual performance criteria become familiar with corporate objectives. Second, the competency evaluation and the quantitative measurement become the main criteria of the performance evaluation system. In addition, training and development activities become familiar with the strategy. And lastly the academy of the bank has gained the quality certificate on the client satisfaction.

In 2012: There is just a little progress about the digitalization.

In 2013: There is not any important changing concerning the HRM.

In 2014: Library (both hard and online) opened. E-learning technology is developed and the training programs catalogue is enhanced.

During the second period (2014-2019):

In 2015, 16, 17 and 18 there is no any important changing concerning the HRM.

In 2019: Manager development programs begin (for the managers from several levels). "Academy hour" begins at the lunchtime break. It aims to contribute the work and life balance of the employees. Training on mobile programs and the video-trainings begin. A new internal communication program begins, in that program the employees present their important anecdotes. And lastly the employees begin to explain their duties to the colleagues.

Evidently newer HRM practices are not very intensive in Bank I. However, we can say that the first period is the leap period and compared ROA average is higher in this period. So, the Bank I supports the hypothesis.

On the other hand, Bank I's lowest ROA are in 2012, 2014, 2016, 2017 and 2018.

Is the 2013's HRM starting intensity bigger than 2012's - No

Is the 2015's HRM starting intensity bigger than 2014's - No

Is the 2017's HRM starting intensity bigger than 2016's - No

Is the 2018's HRM starting intensity bigger than 2017's - No 
Is the 2019's HRM starting intensity bigger than the 2018's - Yes, clearly

Bank I does not support the proposition.

Bank J and its new HRM practices with their starting years.

During the first period (2010-2014):

In 2010: English courses for the employees begin. Lunches with Vice-Presidents, begin for the employees in the training. A new orientation program begins. Training programs are checked and developed. Business school is opened.

In 2011: Only business school is developed.

In 2012: New training programs begin. They aim to leadership development by the presentation of the (organizational) values (for the managers from any level) and by the performance training. The objective of this second one is to guide the managers they can develop their own performance.

In 2013: Recruitment criteria are enhanced with checking the adaptation (capacity) of the candidates to the bank's (organizational) culture.

In 2014: Performance evaluation system is checked and changed. And the training programs are enhanced.

During the second period (2015-2019):

In 2015: Succession planning, work-life balance programs, first steps for the six sigma and the mentoring program, are all begin 2015 .

In 2016: Voluntary trainer program begins for the successful employees. Some of HR staff is prepared for the job evaluation program.

In 2017: A big HR changing program begins. The objectives: Employee loyalty development, brand management program, desired employer program. To reach these objectives a survey is carried out on employees and exemployees. Moreover, focused group meetings are organized. Performance evaluation system is changed and feedback meetings increased. Working from distance begins for one day in a week. Offices are restored and let the employees works in places that they want. Employee-manager meetings begin in order to have strong communication between them. And lastly annual surveys begin to let the employees evaluate the (HRM) activities. In 2018: Discount deals are signed with several universities for master programs. HR IT system is renewed. Meetings between the employees begin in order to have a stronger communication, to show thanks for others and to see the internal career opportunities. "Flexible working hours" and "flexible clothes days" are enlarged. A new reward begins. This new reward is for the employees are inspired because of their any success. Wages and fringe benefits are ameliorated. Leaves for social responsibility projects and for self-development periods begin. Further the coming-back for the employees who terminated their obligatory military services are allowed. New vacations come: Mothers' day vacation, fathers' day vacation, and the first day of the school vacation. Psychological support program begins. Work and life balance seminars begin, a fitness center built. And lastly discounts deals are signed for several art and culture activities.

In 2019: Rotation begins. Employee's suggested candidate system begins. Meetings with the candidates are organized. A special kind of meeting begins: it's for the internal candidates and it aims to explain why they could not come to the position they desire. In addition another kind of meeting begins: it's for the external candidates and it aims to show them their evaluation about the search and selection process. A new leadership development program begins. New born vacation for the father-employees is enlarged. And lastly the ones who have a long working period in the bank are begun to be rewarded.

It is evident that Bank J's second period is the leap period. But the compared ROA is higher in the first period. So, the Bank J does not support the hypothesis.

On the other hand, 2011, 2012, 2013, 2014, 2015 and even 2016 are the years when the lowest compared ROA are recorded. At 2017 the bank J started a new HR program as it is mentioned in the annual. Then, the ROA never goes down, never lower than the average; not anymore. In fact, the Bank J's turning towards the HRM, with a big HR plan, may be an independent case to see the HRM's contribution to the profitability.

Is the 2012's HRM intensity bigger than 2011's - Yes, clearly

Is the 2013's HRM intensity bigger than 2012's - No

Is the 2014's HRM intensity bigger than 2013's - Yes, smoothly

Is the 2015's HRM intensity bigger than 2014's - Yes 
Is the 2016's HRM intensity bigger than 2015's - No

Is the 2017's HRM intensity bigger than 2016's - Yes, very clearly

Bank K and its new HRM practices with their starting years.

During the first period (2010-2014):

In 2010: Unique changing is the adaptation of the promotion program to the carrier planning.

In 2011: Compensation system is checked and adjusted.

In 2012: A new training program for the management candidates started. And secondly, the wages are re-adjusted after a comparison with the market.

In 2013: There is no any important changing concerning the HRM.

In 2014: Unique difference concerns the periods of the performance. It is not two times anymore, it is one time in a year.

During the second period (2015-2019):

In 2015: the bank is acquired by a different group. There is no any changing concerning the HRM.

In 2016: There is no any changing concerning the HRM.

In 2017: Only the bonus types are diversified.

In 2018: Employee satisfaction survey is carried out.

In 2019: Carrier management becomes the base of the training programs.

Not only based on the information explained above, but based on the ones non-explained, it is possible to say that the HRM practices are less in the Bank K, particularly if it is compared with the others. However, it may be said that the first period is a little bit "livelier" then the second period. Similarly, the first period's compared ROA average is higher than the second period. Therefore, Bank K supports the hypothesis.

On the other hand, 2012, 2014, 2015 are the years when the compared ROA are lowers. Neither 2013 nor 2015, 2016 are not years where the newer HRM practices are used as remedy for the ROA problems. In fact, bank K is the one that has no any leap year. So, the Bank K does not support the proposition.

The Bank L and its new HRM practices with their starting years.

During the first period (2010-2014):

In 2010: There are some small modifications on performance evaluation system. And the distance training opportunities are enhanced.

In 2011: Best employer program and talent management are planned.

In 2012: Coaching and mentoring programs begin.

In 2013: Many candidates are promoted and nominated to their new position. And the performance appraisal results become the main bases of the wages.

In 2014: The coaching program is extended for containing the different levels.

During the second period (2015-2019):

In 2015: The suit obligation is finish. Flexible working hours program comes. "The first day of school" vacation comes for the mother-employees. Corporate culture becomes one of the main criteria of the selection step. Corporate culture's principles are announced. Mentoring program begins. And lastly, the strengths and the weaknesses of the corporate culture are measured by a survey.

In 2016: At the beginning of the HR section in 2016 annual report, it is announced that a new HR changing program begins with the aim of supporting the firm strategy. Based on the survey concerning the corporate culture of 2015 a new plan is prepared. In order to applicate this plan, leadership programs for managers begin. The "feedback mediums" are enhanced. Recognition rewards are increased and they become widespread.

Further 2016 changings: Working out of office opportunity begins, for two days in a week. HeforShe of UN begins. Lunch-meetings concerning the work-private life balance for women begin. "School's Last Day" vacation begins for mother-employees. And the renovation works for the buildings of branches begin.

In 2017: Talent management program begins. Search and selection process is changed and it becomes more technologic. Rotation program begins. Performance appraisal system is modified. "The retrospective evaluation view is left" evaluation model will be based on the understanding of the employee's potential and on the reaching 
to it.

In 2018: Data mining works begin and some measured for ameliorating the working climate are taken.

In 2019: There is no any important changing concerning the HRM.

Leap period is obvious for the Bank L. The "lively years" are obvious and it is clearly mentioned that the 2016 was the changing year for the HRM in order to improve the strategy support. Hence the second period is the leap period for the Bank L. Similarly, the average of the compared ROA is higher in the second period than the first period. Bank L supports the hypothesis.

2011, 2013, 2014 and 2015 are the years where the compared ROA is lower than the industry average. If the subsequent years are wanted to be checked:

Is the 2012's HRM starting intensity bigger than 2011's - Yes

Is the 2014's HRM starting intensity bigger than 2013's - No,

Is the 2015 's HRM starting intensity bigger than 2014 's - Yes, clearly

Is the 2016's HRM starting intensity bigger than the 2015's - Yes, very clearly

So, Bank L supports the proposition. But moreover, there is a similarity between Bank L and Bank J: Bank L (like Bank J) started a big HR program in 2016 after the five years with lower compared ROAs (if 2012 exception is ignored) and the ROA never goes down again, after the big HR program (in 2016); not anymore.

Bank $M$ and its new HRM practices with their starting years.

During the first period (2010-2014):

In 2010: Training catalogue is activated. Training catalogue aims to offer many options in order to ensure the chance to choose individual preferences. Voluntary internal trainer program begins. BSC (for the HRM) begins. And the performance evaluation by the subordinates begins.

In 2011: Competency based interview begins. IT for HRM is activated.

In 2012: HR grievance system is activated.

In 2013: There is no any important HRM changing.

In 2014: Some rotation activities are carried out for the branches' staff. (Probably the ones who have the big distance between their home and the branches are replaced in order to make it better).

During the second period (2015-2019):

In 2015: A marketing academy is organized with the contribution of a university in the bank.

In 2016: Training and development programs are transformed to the games for the new generations. And some small wage modifications are carried out.

In 2017: Innovation academy is founded. And managerial improvement program begins.

In 2018: There is not any important changing concerning the HRM. However; a new technology leap is seen in second period. Although the starting year is not known, it's clear that it begins in the second period. So; we can add the technologic improvement in the second period.

In 2019: Employee loyalty become important. In that frame photograph competition, cultural events sportive tournaments begin.

Although the Bank M's leap period is not very clear we may consider that it was the second period, particularly because of 2017 and 2019. Similarly, the average compared ROA is higher in the second period. Hence, the Bank M supports the hypothesis.

However, it does not support the proposition. Because the lowest compared ROAs are recorded in 2011, 2012, 2014 and 2017, but only in 2015 a new movement of HRM practices realized.

Bank $\mathrm{N}$ and its new HRM practices with their starting years.

During the first period (2010-2014):

In 2010: Carrier school opening is planned.

In 2011: Performance evaluation system is modified and BSC based objectives are added to the system who has already competency-based criteria. And the results of this newer performance appraisal system are begun to be 
used in the compensation, promotion and the bonus systems. And all HRM practices are checked. Moreover, the HR unit begins to visit the branches in order to be informed about the demands, grievances and problems.

In 2012: Talent management begins. Compensation committee is organized. And compensation committee analyzes the wages' market and it makes benchmark agreements with other banks (names are not mentioned) in order to find the best salary.

In 2013: Grievance line is opened. Ethic values come into performance system in addition to competency and objective based criteria. Compensation committee's works become regularly. Leadership center is opened in order to support the talent management by improving the managers leadership skills. And lastly, the distance training and development programs are transferred into the mobiles.

In 2014: Carrier school is opened in order to have a better efficiency for the training programs in class. And the new measurement systems for evaluating the training efficiency are driven.

During the second period (2015-2019):

In 2015: The BSC based performance evaluation system is extended in order to include the employees who were not included before.

In 2016: Leadership school is extended.

In 2017: There is no any changing concerning the HRM.

In 2018: Employee's loyalty survey is carried out. And feed-back meetings are organized about the survey.

In 2019: Competencies are modified. The selection interviews are transformed to the competency-based interviews. A new "organizational sales culture" project is prepared in order to create and diffuse the common objectives and principles of it, in the frame of the sales staff.

In second period, only the activities in 2019 seems like lively; however, they are generally only the projects. So, the first period is considered evidently the leap period for Bank $\mathrm{N}$. The first period is meantime the period when the average compared ROA is higher. Therefore, Bank N supports the hypothesis.

About the proposition; Bank N has many years of lower compared ROA, such 2011, 2013, 2014, 2015, 2017, 2018 and 2019. As it can be seen below; Only 2018 and 2019 are the years where the newer HRM practices starting are high.

Is the 2012's HRM starting intensity bigger than 2011's - No

Is the 2014's HRM starting intensity bigger than 2013's - No

Is the 2015's HRM starting intensity bigger than 2014's - No

Is the 2016's HRM starting intensity bigger than 2015's - No

Is the 2018's HRM starting intensity bigger than 2017's - Yes

Is the 2019's HRM starting intensity bigger than the 2018's - Yes, clearly

So, the Bank $\mathrm{N}$ does not support the proposition.

Bank $\mathrm{O}$ and its newer HRM practices with their starting years.

During the first period (2010-2014):

In 2010: There is no any changing concerning the HRM.

In 2011: That's the "big merger" year. It is "big" because two big international groups are merged and their banks in Turkey are merged also. In the annual it is mentioned that the HRM practices aim to ensure a good adaptation between two different banks' organizations as well as staff for 2011. Secondly the individual training program preferences are begun to be taken in account. But the catalogues still don't exist. "HR desk" is opened. The desk is in charge for the staff's problems, grievances and desires.

In 2012: A new program of "best working project" is activated in order to let the employees be familiar with the corporate culture. Employee's handbook is published for a good orientation. Employee satisfaction surveys begin. And the ex-employees begin to share their experiences.

In 2013: Participation to the universities" "carrier day" event begins. Social media become more important. A new platform, that aims to take the employees into the decisions, is activated. And the educations for the obligatory licenses and the certificates begin.

In 2014: Controversy mentoring begins. Private-work life program is talked. The entrepreneurship program within the organization begins; further this program is unified with the organizational innovation and organizational angel investor programs. This year has many important changings concerning the training activities: 1) Individual development plans begin for all employees 2) More detailed plans for "Higher Performers" are driven 3) 
Leadership Academy is opened. In the frame of this academy some programs are modified and hugely improved such "executive leadership", "performance management", "coaching trainings", "management skills development programs”, “360 Degrees”, "trainings for Y Generation”, "Stress Management trainings”. (If it's necessary, the trainings are realized out of the bank) 4) The consultancy services for corporate clients are developed 5) Agricultural expertise program for employees is developed to have a better consultancy capacity for the agricultural enterprise clients 6) Training and exams are organized to reduce errors in operational activities.

During the second period (2015-2019):

In 2015: Only a new (internal) certificate program begins (with the contribution of a university. That's the special banking certificate.

In 2016: Internal Carrier Festival is carried out. The aim is to meet employees with the managers of the different units/departments in order to inform them about the positions in different departments that they may imagine to go. Profitability based the branch program as well as its training program begins in 2016. Moreover, another new training program begins: the different employees, even from different countries, will share their experiences with this new program.

In 2017: New training programs begin concerning the client profitability (in addition to the branch-based profitability). Competency improving programs are redesigned with the aim to improve the leadership skills of the managers from different levels.

In 2018: Client-oriented changing program begins. In accordance with this program a new center is opened for creating and developing of the client-oriented service culture in the bank. And a new game for employees is driven; this game will test and show (to the employees) whether their behaviors are familiar with the client satisfaction or not.

In 2019: The changings concern generally the principles and priorities in bank's view but not about the practices. The difference in action is merely the opening of the new internal academy that aims to improve the digital literacy.

Bank $\mathrm{O}$ is one of the difficult banks for deciding the leap period. Nevertheless, we may consider that the first period can be considered as the leap periods particularly since the 2014's contributions. But its higher average of compared ROA exists in the second period. So, the Bank O does not support the hypothesis.

On the other hand, the lower ROA levels are recorded in 2011, 2016 and 2017.

Is the 2012's HRM intensity bigger than 2011's - Yes

Is the 2017's HRM intensity bigger than 2016's - No

Is the 2018's HRM intensity bigger than the 2017's - Yes, clearly

Based on these data above, it possible to say that the Bank O supports the proposition.

\section{Bank $\mathrm{P}$ and its newer HRM practices with their starting years.}

During the first period (2010-2014):

In 2010: A couple of new program begins in order to meet the managers and the employees: "meeting with the managers" program and "opened door" program. Internal client satisfaction surveys begin. Employees' suggestion system is checked and renewed. Internal service units' quality improvement program begins. And the trainings based on the individual preferences begin.

In 2011: Social responsibility programs increased (it is mentioned in HR section). Discount agreements are signed with the firms that the employees purchase. Some hobby training activities are carried out.

In 2012: There is an important HR changing program is driven including: online interviews, employee loyalty surveys, coaching programs, individual leadership and development programs. Evaluation center is organized. And lastly the distance training and development programs begin.

In 2013: Employee's candidate reference program begins. And the common (organizational) culture is added into the training objectives.

In 2014: A photograph competition is organized and a theatre club is opened.

During the second period (2015-2019):

In 2015: HR IT system is renewed. Couching programs begin. "Merci between the employees" program begins and the most recognized employees are rewarded. Discount agreements with the universities are signed. "Welcome calls for the new entries" program begins. Performance appraisal system is simplified and only the competencybased criteria continue. 
In 2016 and 2017: There is no any important changing concerning the HRM.

In 2018: training programs for some obligatory certificates are carried out.

In 2019: "School's Last Day" vacation, and the "First day of the school" vacation begin. "Being father vacation" extended to 10 days (instead of the 5 days). Marriage vacation extended to 5 working days instead of five calendar days. Suit obligation is finish for headquarter staff. An Ataturk's mausoleum visit is organized. And the summer party is organized.

In spite of the activities in 2015 and 2019, the first period (particularly 2012) is good to be the leap period for the Bank P. In meantime, the average of compared ROA is higher in the first period. Hence the Bank P supports the hypothesis.

Bank $\mathrm{P}$ is excluded in the questioning of the P1. Because the lower compared ROAs are recorded in 2015, 2016, 2017, 2018 and 2019. When the subsequent years of these ones are checked:

Is the 2016's HRM starting intensity bigger than 2015's - No

Is the 2017's HRM starting intensity bigger than 2016's - No

Is the 2018's HRM starting intensity bigger than 2017's - Yes, smoothly

Is the 2019's HRM starting intensity bigger than 2018's - Yes, obviously

And we don't know the HRM in 2020. Hence, we cannot reach to any result about the causality.

Bank R and its new HRM practices with their starting years.

During the first period (2010-2014):

In 2010: There is no any changing concerning the HRM.

In 2011: The compensation committee is organized (but it is only organized).

In 2012: The competencies added into the performance appraisal criteria. And internal clients (satisfaction) surveys begin.

In 2013: Norm cadre begins. The training programs for improving the managerial and leadership skills of the managers begin. And the Worlds' Economic Forum's Agreement against sexism is signed.

In 2014: There is not any changing concerning the HRM.

During the second period (2015-2019):

In 2015: Some the arrangements about the duties and authorizations of some positions are carried out.

In 2016: There are only small modifications about the performance appraisal system.

In 2017: A rotation program is driven for the branches staff in order to improve to motivation, to dynamism and to avoid of the risks since the working together for longtime in a unique branch. A reconstruction program begins for mainly the headquarter staff in order to improve the operational speed and efficiency. Training programs for the obligatory certificates begin. Internal trainers training program begins. And the criteria for the promotion are designed as well as the training programs for these criteria begin.

In 2018: Talent management begins. "Welcome pocket sending" program for new entries, begins. Employee loyalty surveys begin. And the equipment that measure the entry and exit times of the employees are placed and activated.

In 2019: Employee suggestion platform is activated. The platform is good to receive the employees' grievances in meantime in order to reduce the voluntary leavings and to take the necessary measures by listening the critics. Conferences begin. These conferences are carried out by the experts about their domain. The domains are several that the employees demand. And they can listen with their family. Back-up program for critical positions begins.

It is obvious that the second period is the leap period for the Bank R. And the average of the compared ROA is higher in the second period. Hence the Bank R supports the hypothesis, too.

What about the proposition? 2012, 2014, 2016, 2017 are the years where the lowest ROAs are recorded. When the subsequent years of those are analyzed about their HRM leap:

Is the 2013's HRM intensity bigger than 2012's - Discussable

Is the 2015's HRM intensity bigger than 2014's - Yes, smoothly

Is the 2017's HRM intensity bigger than 2016's - Yes, clearly

Is the 2018's HRM intensity bigger than the 2017's - Yes

The Bank R is one the obvious cases who support the proposition. 
Bank $\mathrm{S}$ and its new HRM practices with their starting years.

During the first period (2010-2014):

In 2010: Employee hotline is activated. A new creche is opened.

In 2011: Training activities begin in the abroad branch.

In 2012: The cooperation with universities are enhanced; participations to the carrier days etc.

In 2013: Talent management begins. Discount agreements with the universities on the master programs begin.

In 2014: A new HR web site is activated for receiving the applications and a new carrier web site is activated. New carrier web site has a demo of orientation program. In 2014 HR call center is reorganized and divided in three as HR-IT service, call HR and HR adviser (for the financial, psychologic, health and legal questions). And a new activities program starts. This contains the seminars, videos etc. for the private-working life balance.

During the second period (2015-2019):

In 2015: "Face to face carrier interviews" start for the branches' employees

In 2016: There is not any changing concerning the HRM.

In 2017: A partnership is agreed with a university for a new master program concerning the data mining.

In 2018: Brand management and back-up programs start.

In 2019: Carrier map program is extended for taking the branches' employees in. Performance appraisal system is renewed and the evaluations are multiplied as twice in a year instead of once.

It is possible to say that the newer HRM practices are more intensive in the first period (2010-14) and the first period's compared ROA average is higher than the second one's. So, the Bank S supports the hypothesis.

On the other hand; 2011, 2012, 2014, 2015 and 2017 are the years where the lower ROAs are recorded.

Is the 2012's HRM starting intensity bigger than 2011's - Yes, smoothly

Is the 2013's HRM starting intensity bigger than 2012's - Yes

Is the 2015's HRM starting intensity bigger than 2014's - No

Is the 2016's HRM starting intensity bigger than 2015's - No

Is the 2018's HRM starting intensity bigger than the 2017's - Yes, clearly

So, the Bank S supports the proposition.

Bank T and its new HRM with their starting years.

During the first period (2010-2014):

In 2010: Online recruitment is extended for reaching all levels and departments. A new "call center line" is founded for the employees' questions about their private life. And the "face to face meetings" with branches' staff started. The objective is to improve the internal communication.

In 2011: There is not any changing concerning the HRM.

In 2012: First, the duties are reorganized as the ones concerning the operation and the ones concerning the sales and marketing. And the certification programs started for the ones whose duty will change. Secondly wage system is reorganized. The performance appraisal system is extended for the branches' staff. And the evaluation results are used for the bonuses.

In 2013: There is a little modification of wage system; the ones, whose promotions are delayed, have obtained a supplementary paying. And the internal transferring demands are evaluated.

In 2014: There is not any changing concerning the HRM.

During the second period (2010-2019):

In 2015: A new "manager developing program" starts. The criteria of the performance appraisal system are modified.

In 2016: There is not any changing concerning the HRM.

In 2017: There are some little modifications concerning the wage system.

In 2018: The competencies are added into the performance appraisal system's criteria.

In 2019: There is not any changing, but the plans for 2020.

Bank T's leap period is the first period. However, its higher compared ROA average is in the second period. So, 
the Bank T does not support the hypothesis.

On the other hand, Bank T's lower compared ROA years are 2011, 2016 and 2017

Is the 2012's HRM starting intensity bigger than 2011's - Yes,

Is the 2017's HRM starting intensity bigger than 2016's - Yes

Is the 2018's HRM starting intensity bigger than the 2017's - Yes, smoothly

Hence the Bank T supports the proposition. 